\title{
Kitap Tasarımında Ortak Yazarlık
}

\section{Co-authorship in Book Design}

\section{Umut Altıntas}

Dr. Öğrt. Gör., Yaşar Üniversitesi Sanat ve Tasarım Fakültesi Grafik Tasarım Bölümü email: umut.altintas@yasar.edu.tr (DORCID ID: https://orcid.org/0000-0001-7951-5178

$\checkmark$ iThenticatenters \& Researchers

Atıf (APA 6)/To cite this article

Altıntaş, U. (2020). Kitap tasarımında ortak yazarlık. Atatürk Üniversitesi Güzel Sanatlar Enstitüsü Dergisi, 26(44), 181-201. doi: https://doi.org/10.35247/ataunigsed.683363

Makale Gönderim Tarihi/Received: 02/02/2020

Makale Kabul Tarihi/Accepted: $01 / 03 / 2020$

Makale Yayın Tarihi/Published: 19/03/2020

Review Article / Derleme Makalesi

Öz

$\mathrm{Bu}$ çalışma, postmodern dönem kitap tasarımında grafik tasarımcının ortak yazar olarak yer aldığ 1 altı adet kitap tasarımı incelemesini içermektedir. Dönem ve içerik olarak birbirlerinden ayrılan bu kitapları aynı kategori içerisinde bir araya toplayan esas dürtü, grafik tasarımcının yalnızca ona verilen içeriği okunur ve görünür hale dönüştürme sorumluluğu değil, aynı zamanda o içerik hakkında da söz ve yorum sahibi olma ayrıcalığıdır. Bu ayrıcalığın adı "müellif tasarımcı"dır. Yazar ile tasarımcının eş konumda bir arada çalışarak kitap nesnesini var ettikleri bu anlayıs, özellikle 1970 sonrası postmodern tasarım anlayıșında, tasarımcının bireysel özgürlüğünü ilan etmesiyle karşımıza çıkmaktadır. Avrupa'da modernist tasarım normları yavaşça terk edilmeye başlanması ve teknolojinin ilerlemesiyle üretim biçimlerinin daha demokratik ve kolay ulaşılır hale gelmesiyle, hatta tüm bunların da ötesinde tasarımın evrenselleşmesi, tasarımcıya bireysel olabilme imkanını tanımıştır. Araştırma içerisinde yer alan örnekler, yayımlandığı dönemde es yazarlık bağlamında ses getirmiş, tasarımıyla ana akım kitaplardan sıyrılmış ve kitap tasarımı anlayışına yeni bir nefes sağlamıştır.

Anahtar kelimeler: Ortak Yazar, Müellif, Kitap Tasarımı, Postmodernizm

\begin{abstract}
This study includes six book design critics in which the graphic designer as a co-author in postmodern era. The main impulse that collects these books -which are separated from each other in terms of period and content- in the same category, is not only the responsibility of the graphic designer to make the content read and visible, but also the privilege of having a say and comment on that content. The name of this privilege is "designer as author". This understanding, in which the author and the designer work together in a peer position, and create the book object, emerges when the designer declares individual freedom, especially in the postmodern design understanding after 1970. Especially in Europe, modernist design norms have given the opportunity to be abandoned slowly, with the advancement of technology, the production forms become more democratic and easier to reach, and above all, the universalization of the design allowed the designer to be an individual. The examples included in the research made a sound in the context of co-authorship at the time of their publication; they were stripped of the mainstream books with their design and provided a new breath to the book design understanding.
\end{abstract}

Keywords: Authorship, Author, Book Design, Postmodernism

\section{Giriş}

Bu araştırmanın temel dayanağı olan "yazar olarak grafik tasarımcı" ifadesi; metnin içine karışan, yorumlayan, yapı kuran, izah eden, mana veren, içeriğe soyunan, içerikle boğuşan, içeriğe meydan okuyan, bilgiyi yeniden üreten, iletinin biçimsel aktarımını değiştiren, okumayı görsel deneyime çeviren, metne yeni anlam ve yeni okuma önerisi getiren kişiye referans vermektedir. Bu tanımlar, 1930'lar ile başlayıp 1960'ların sonlarına kadar devam eden modernist tasarım anlayışının katı kurallarının zıttı olarak karşımıza çıkmaktadır. Rasyonel, grid sistemlerine dayanan ve tasarımcıyı anonim tutan modernist tasarım anlayışının ardından 1960'lar ve sonrası, tasarımcının adını ön plana çıkartan yaratıcılığın devrimi ve grafik tasarımda kavramsal bir atılımın başlangıcı kabul edilmektedir. Bu bütünsel postmodern nosyon, 1970'ler ile birlikte Wolfgang Weingart'ın tipografide deneysel ve bireysel yaklaşımıyla başlamış, 80'lerde Crabrook Sanat Akademisi ile Katherine McCoy'un öncülüğünde bir eğitim modeli haline gelmiş, 90'lara geldiğimizde ise Rudy VanderLans ile birlikte Avrupalı ve Amerikalı tasarımcılar arasında bir beyana dönüşmüştür. Kaldı ki 80'lerden itibaren kişisel bilgisayarların tasarımcıların atölyesi haline gelmesiyle masaüstü yayıncılık da yaygınlaşmış, "biçimsel yazarlık" eğilimi de tasarımcının bireysel deneysel yaklaşımlarıyla birlikte artmaya başlamıştır.

80'lerden itibaren grafik tasarım tartışmalarının merkezinde olan grafik tasarımcının yazar rolünde bahsi geçen "yazar" ifadesi, tasarım alanına "biçimlendirme" gibi daha edilgen bir işlevden ziyade, içerik ve anlam yaratmaya yönelik daha etken bir anlamda kullanılmaktadır. İngilizce'de author olarak kullanılan, Türkçe'de karşılığını müellif kelimesinde bulan tanımı, bu makalenin kimi yerlerinde yazar olarak kullanmaya devam edeceğiz. Çünkü verilen örneklerde de görüleceği üzere bahsi geçen yazarlık, bir anlamda "biçimsel" yazarlıktır. Bu yaklaşım tasarımcının rolünü yeniden düşünmeye iten bir model ve aynı zamanda yazar ile tasarımcıyı aynı denklikte yaratıcı (iş ortaya çıkartan, sahiplenen) olarak kabul eden bir devire işaret etmektedir. 
Grafik tasarımcının biçimsel yazarlığını en iyi kullandığı yer, bu makalenin de konusu olan kitap tasarımı olarak karşımıza çıkmaktadır. Modernizm döneminin grid ile sınırlı biçimlendirme alanında tasarımcıların kitap tasarımında ortaya çıkardıkları kurallar ve yenilikler, dijital medya ile değişen görsel anlatım biçimleriyle yıkılmıştır. Metnin, modern tasarım gramerleriyle ifade edildiği görsel yazarlık denemelerinin ardından tasarımcılar, kitaba yeniden kurulması gereken bir yapı olarak bakmışlar ve içeriğe katkıda bulunan bireysel ifade biçimlerini kullanmaya başlamışlardır.

1960’lar itibariyle görsel medya kültürünün değişime uğraması ve dijital çağın başlamasıyla kitabın okunma biçimi ile tasarımcının yayıncılık endüstrisindeki rolü de değişmiştir. Bilgisayar, televizyon, video ve dijital medyanın görsel etkisi kitap mecrasının da okunma biçimini etkilemiştir. Medya kültürünün görsel dinamikleri, kitabın alışılageldik durağan sayfa yapısına zıtlık oluşturmuştur. Bu yüzden kitap nesnesinin anlatım dili, ardışık sayfaların aralarındaki iletişim ve dinamik sayfa düzeni ile söz gelimi hareketli medyanın basılı arayüzüne dönüşmüştür.

Dijital teknolojideki ilerlemeler de bir yandan grafik tasarım pratiğini kökten değişsirmiştir. Bu değişimle birlikte tasarımcılar çalışmalarındaki üretim süreci üzerlerindeki kontrolü daha fazla ele almışlardır. Bilgisayar teknolojisi harf dizimi, sayfa düzeni ve fotomekanik teknikler gibi kitap tasarımı ve üretimi sürecindeki birçok aşamayı bütünleşik hale getirmiş ve tasarımcılar artık biçimin nasıl üretileceği hakkında zaman harcamaktan çok, içeriğine odaklanmaya başlamışlardır. Masaüstü yayıncılığın ilerleyişi, tasarımcıyı tüm üretim sürecinin başat aktörüne dönüştürmüş; bunun getirisi olarak tasarımcılar yazar gibi davrandıkları bir tasarım modelini geliştirmişlerdir.

"Yazar olarak tasarımcı" fikri, -bu makaledeki örneklerin de göstereceği gibi- tasarımcının bilinen anlamda kitap yazmasından ziyade, o kitabın konseptini geliştiren, içeriğini oluşturan, başlatan kişi anlamında kullanılmaktadır. Yazar tasarımcı modeli, bir müşterinin yönbilgisine bağlı kalmadan veya ihtiyaç duymadan, tasarımcının bir inisiyatif ele alarak projenin bağlamını kendisinin oluşturmasına ve üretmesine bağlı bir modeldir. Böylece tasarımcı, kitap tasarımı aracılığıyla kendi yorumunu ve entelektüel bakış açısını özgürce yansıtabilmektedir. Özetle, yazar tasarımc1; müşteriye bağlı olmaksızın veya kimi örneklerde müşteri ile iş birliği içerisinde, kişisel bir ifade biçimi olarak kitap tasarımında içeriği yaratan veya inşa eden kişidir. Burada ise bahsi geçen yaklaşımla üretilmiş altı örnek ve tasarımcıların yöntemleri incelenerek tasarımda yazarlık süreci daha derin olarak irdelenecektir.

İnceleme, Marshall McLuhan'ın dünyaca üne kavuşmuş olan The Medium is the Message mottosunun kitabıyla başlamaktadır. Tasarımcı Quentin Fiore'nin ise bu kitabın oluşumunda en az yazarı McLuhan kadar katkısı bulunmaktadır. Fiore'nin metne eşlik edecek olan görsellere ve onların yerleşimine karar vermesi, metnin kitap boyunca dağılımı, özetle kitabın okunma biçimine olan yaklaşımı, onu tasarımcı olarak en az yazarı kadar eş yazar pozisyona taşımış, sırf bu yüzden kitabın kapağında isimleri birlikte yer almıştır. İkinci inceleme, bir ders kitabı olarak güzel sanatlar akademilerinde de sıklıkla başvurulan John Berger'in Görme Biçimleri kitabına aittir. BBC'de dört bölümden oluşan bir televizyon serisi olarak başlayan içeriğin kitaplaşmasında ve programdaki interaktif anlatı formatının kitabın basılı formatının sunduğu imkanlar dahilinde devam edebiliyor olmasında tasarımcı Richard Hollis'in payı büyüktür. Üçüncü incelemede yazar Ferit Edgü ve tasarımcı Bülent Erkmen birlikteliğinden ortaya çıkan Kitap isimli kitabın üretilme serüveni yer almaktadır. Ana akım yayıncılıktan alışkın olduğumuz; öncelikle metnin yazıldığı, sonra tasarımın yapıldığı süreç, Kitap ile birlikte tersine çevrilmiş, önce kitap tasarlanmış, sonra o kitaba yazı yazılmıştır. Bir sonraki inceleme ise yine Bülent Erkmen'in, Sevim Burak'ın Yanık Saraylar eserine önerdiği yeni tipografik yaklaşım ve onunla birlikte doğan edebiyatçı-tasarımcı tartışmalarına ayrılmıştır. Son iki kitap, birbirlerine yakın zamanda yapılmış ve ikisi de yayıncılık dünyasında simge haline dönüşmüş denemelerdir. İlki mimar Rem Koolhaas ve tasarımcı Bruce Mau işbirliğinden türeyen S,M,L,XL, tasarımı ve cüssesiyle bir mimarlık ve kitap manifestosuna dönüşürken ve ikisinin adı kapakta yer alırken, Irma Boom'un tasarladığı SHV Thinkbook örneği ise tasarımcıya sonsuz özgürlük ve güven verildiğinde, kitap nesnesi aracılığıyla bir petrol şirketi için bile ne kadar avangart bir söylem kurulabileceğini göstermektedir.

\section{Yöntem}

Bu yazıda "biçimsel yazarlık" ve "ortak yazarlık" kavramlarının daha iyi anlaşılması için altı adet kitap örneği inceleme altına alınmıştır. Bu kitaplar zaman ve tür bakımından birbirlerinden görece uzak olmakla beraber, yaklaşımları ve yapılanma arka planı birbirlerine oldukça benzemekte, hatta birbirlerini doğrulamaktadırlar. Yöntem olarak, öncelikle literatür taraması sonucunda farklı kaynaklarda benzer yaklaşımlarda bahsedilen bu kitaplar, "biçimsel yazarlık" anahtar kelimesi altında bir araya getirilmiş, ardından her bir örnek bizzat incelenerek teorik altyapılarına uygun biçimde yorumlanmıştır. Kitaplar, kronolojik olarak sıralanmıştır.

\section{Marshall McLuhan, Quentin Fiore: The Medium is The Massage}

"Kâğıt üzerinde hareket eden bir tasarım. Gözü ve zihni, metin ve görseller arasında hızlı bir tempoda okutmaya zorlayan devinimsel olarak yerleştirilmiş, iki kapak arasında duran film gibi.” (Schnapp ve Michaels, 2012, s. 14). 
Bir ortak yazarlık süreci olarak tasarımcının konumu ve rolünün tartışılmaya başlandığı postmodern çağda yayımlanan The Medium is the Massage (1967) (Görsel 1), tasarımcının kapakta adı yazarla eş olarak yer aldığ 1 bilinen ilk örnektir. Tasarımcı Quentin Fiore'nin adı, Marshall McLuhan ile birlikte aynı boyda, eşit şartlarda yer alarak dönemin -özellikle karton kapak- yayımcılık geleneklerinin hiyerarşisini tam tersine çevirmiştir (Schnapp ve Michaels, 2012, s. 218-220).

Kitabın ortak yazarı olan Fiore bu kitapta McLuhan'ın teorilerinin görsel yorumlayıcısı konumundadır. Kitabın oluşum sürecinde McLuhan yazdığı metinleri, kitabı tasarlaması için Fiore'ye teslim etmiştir. Fiore, kitabın dağınık malzemelerini kendi uygun gördüğü bir yapıyla ve kendi uygun gördüğü imgelerle yan yana getirerek bir öneri sunmuştur (Karol ve Tanyeli, 2007). Fiore'nin bu yaklaşımı, kuşkusuz kitabın okunma biçimini de etkilemiştir. McLuhan'ın metinleri ile kopmaz bir bütün olarak yer alan görsel seçimleri ve yerleşimleriyle Fiore, bir anlamda kitabın editoryal ve küratoryal kurgusuna da karar vermiştir. İçeriğe yaptığı bu müdahale ile adının ortak yazar olarak kapakta yer almasını sağlamıştır (Bilak ve Bailey, 2005a).

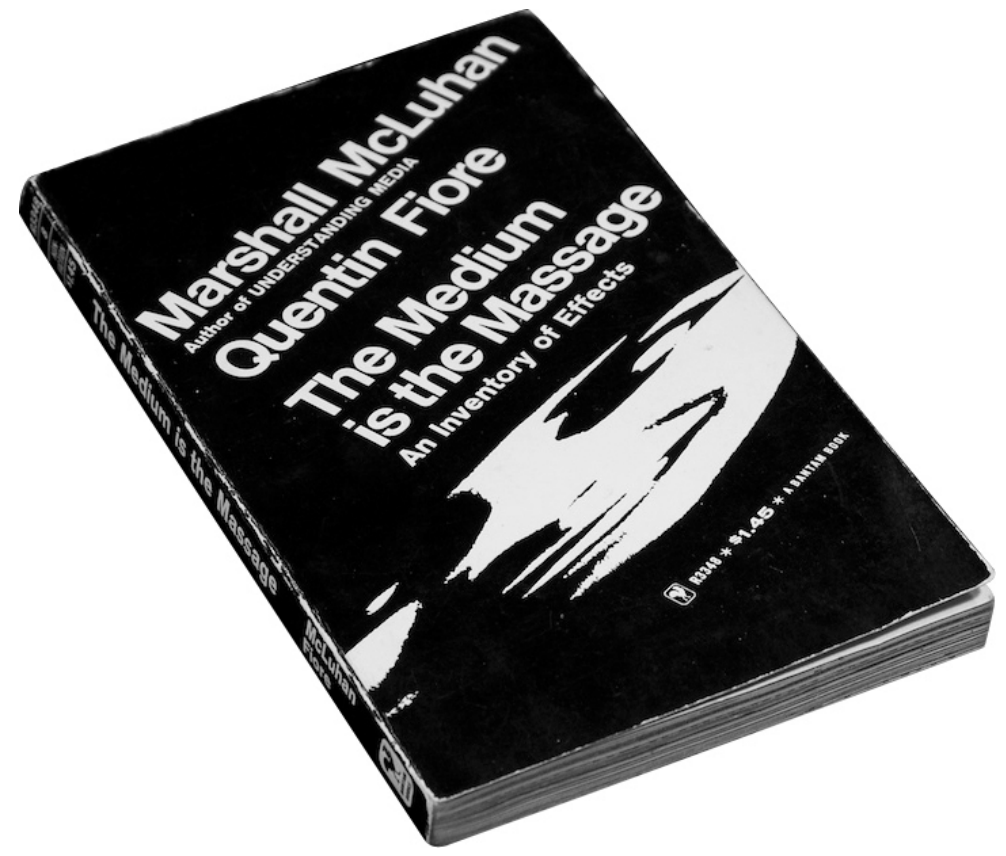

Görsel 1. The Medium is the Massage kitabının kapağı.

Quentin Fiore, kitapta, ana akım kitap yayıncılığ normları içerisinde McLuhan'ın zorlayıcı metinlerini uzman olmayan okuyucuların da anlayabileceği görsel okumalara tercüme etmiştir. Kitabın ana dili, içeriğe özgü tipografi ve imge kullanımıyla bir görsel-metin sentezidir. The Medium is the Massage ve onun üretim süreci, yayımcılık endüstrisinin; "kitabı yazarlar yapar, editörler düzenler, tasarımcılar tasarlar" gibi basmakalıp prosedürlere bağlı kalmanın ötesine geçen bir eş yazarlık örneğidir (Schnapp ve Michaels, 2012, s. 219).

İçerik ve biçimin birbirine sarıldı ̆̆ ve okuyucusuyla etkileşim halinde olan kitap, ana akım yayıncılıkta endüstriyel standartların gerektirdiği baskı olanakları içerisinde yeniden düşünülerek ve bu normları tersine çevirerek eşine az rastlanır bir anlayışta tasarlanmıştır. Mevzubahis yayıncılık kalıplarına göre The Medium is the Massage "kitap olmayan bir kitap"tır.

Fiore, kitabın her sayfasında kullandığı metin-görsel birlikteliği fikrini McLuhan'ın önceki yazdıklarından referans alarak oluşturmuştur. The Medium is the Massage'nin ana kaynağı, McLuhan'ın Gutenberg Galaxy (1962) ve Understanding Media (1964) kitaplarıdır. Bu iki kitabın zorlayıcı dili nedeniyle eleştirilen McLuhan, Fiore ile birlikte The Medium is the Massage ile söz gelimi daha popüler ve kolay anlaşılır kitap yapma isteğiyle Antik Yunan heykellerinden New Yorker çizgi film imgeleriyle örülü teorik bir kolaj ortaya koymuştur (Lupton ve Miller, 1999, s. 91-107).

Quentin Fiore'nin eş yazar olarak kapakta adının geçmesi dışında dikkat çeken bir diğer unsur, McLuhan'ın ünlü "The Medium is the Message" mottosunun kapakta "massage" olarak yazılmış olmasıdır. Belli kaynaklara dayalı olmasa da McLuhan başlığın dizgide hatalı yazıldığını gördükten sonra bu şekilde kalmasını daha uygun gördüğü söylentiler vardır. Hatta Popova'ya (2012) göre, massage, "mass-age" gibi bir kelime oyununu içermektedir.

Kitap, dönemin yayıncılık düsturuna bağlı olarak konvansiyonel okuma alışkanlığından uzak olduğu için 17 yayıncı tarafından reddedilmiş, en sonunda Bantam Yayınevi tarafından karton kapaklı 35.000 kopya üretilmek 
üzere kabul edilmiştir. Kitabın başarısıyla birlikte 35.000 kopya daha basılarak Almanya, Portekiz, İspanya, Japonya ve İtalya baskıları dünya çapında milyona yakın dolaşım sağlamıştır (Lupton ve Miller, 1999, s. 91-107).

Fiore, verilen düşük bütçe ve kısıtlı zaman nedeniyle, kitaba daha çok melez bir bakış açısıyla yaklaşmak zorunda kalmıştır. Saylafar, bir imaja eşlik eden veya tek başına bir başlık gibi duran büyük harflerle yazılmış kısa cümleleri bir arada tutmakta ve McLuhan'ın kelime oyunlarına görsel oyunla eşlik etmektedir. Kitap içerisindeki görsel-metin birlikteliğiyle Fiore, Moholy-Nagy'nin Malerei, Fotografie, Film kitabiyla icat ettiği "tipofoto" üslubunun devamlılı̆̆ını getirmiştir (Schnapp ve Michaels, 2012).
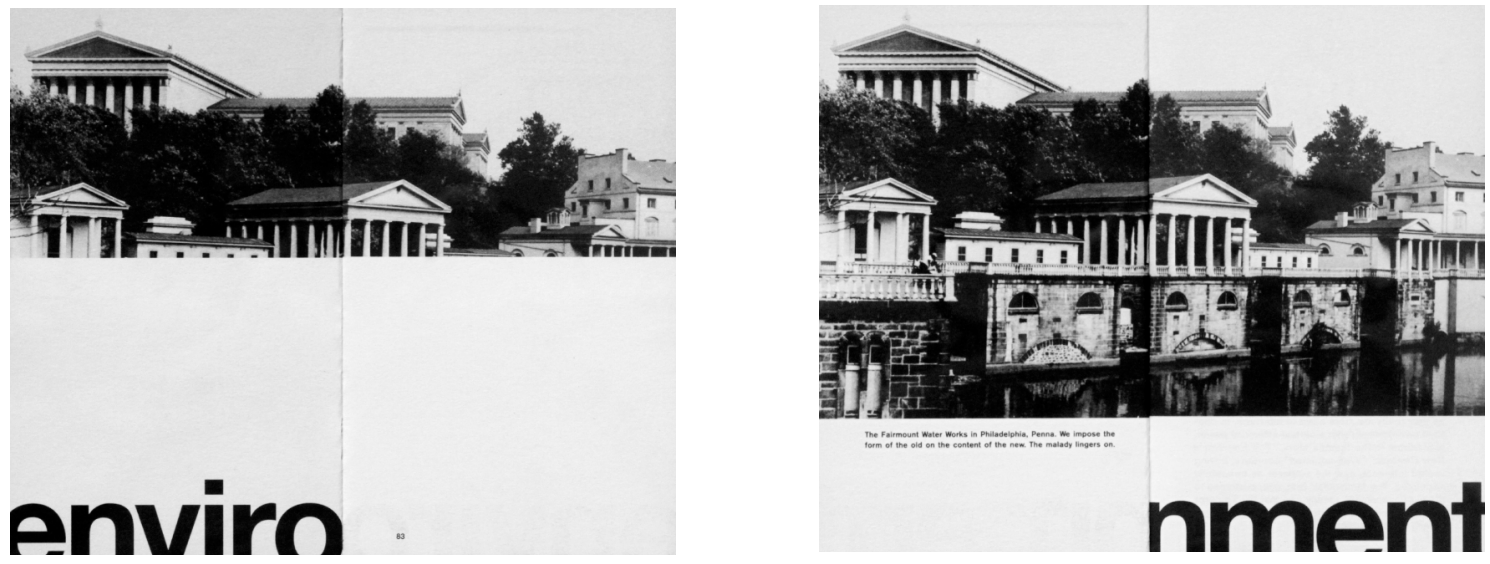

Görsel 2. The Medium is the Massage, görsel ve tipografik akışın görüldüğü ardışık sayfalar

İçeriğin bir parçası olarak sayfalar boyunca dizgiye eşlik eder biçimde kitaba yayılan beyaz alanlar, kitabın en göze çarpan biçimsel kararlarından biridir. Boşluk, kitabı daha kolay okunur kılan plastik bir unsurdur. Bazı sayfalarda büyük yerleştirilmiş bir imaj, ardından gelen sayfada pul boyutunda yeniden kullanılmıștır (Görsel 3). Kitap boyunca tekrar eden bu kurgu, yazılarla bitişik veya ayrı kullanılmasına bağlı olarak imajların her seferinde farklı anlamlarda okunmasına olanak tanımıştır. Bu yaklaşımıyla Fiore, geleneksel bir kitabın "resim altı yazısı" ve "metin-illüstrasyon" hiyerarşisinin istikrarını bozmuştur (Lupton ve Miller, 1999, s. 91-107).
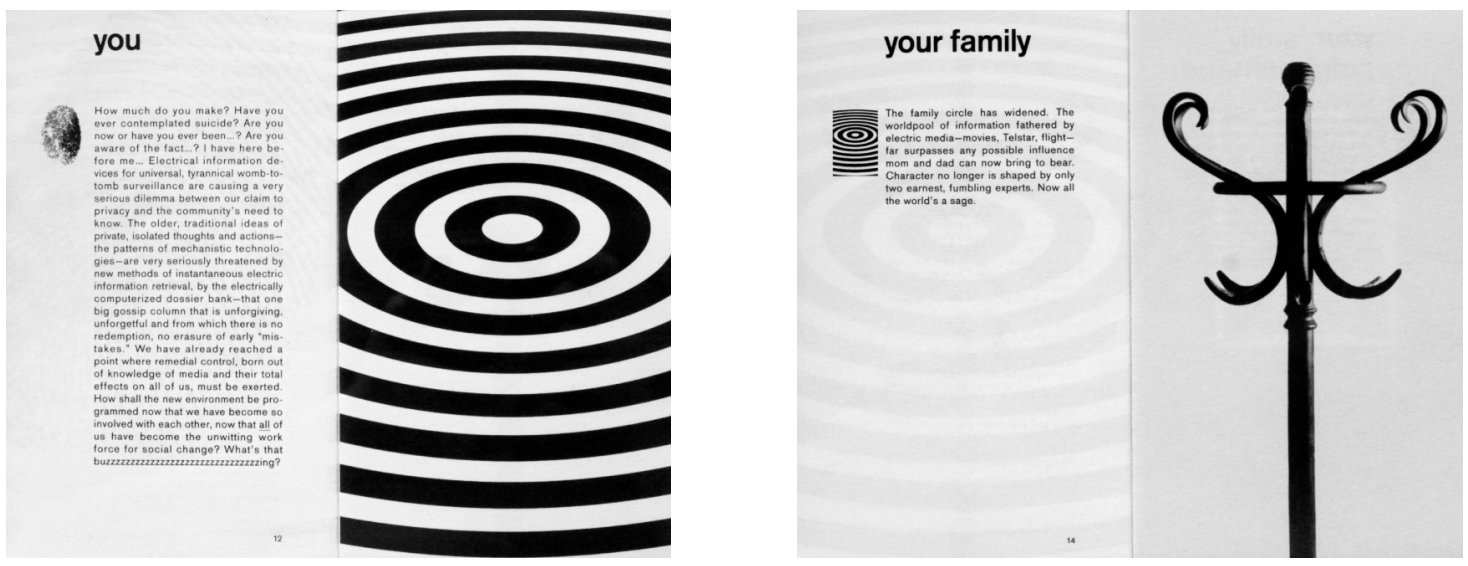

Görsel 3. The Medium is the Massage, tam sayfa bir görselin bir sonraki sayfadaki pul boyutundaki kullanımına örnek

Kitabın en öne çıkan jestlerinden bir tanesi "the book is an extension of the eye" (Görsel 4) mottosunun yer aldığ ardışık sayfalarda kitabı açık bir şekilde tutan iki parmaktır. "the book" yazan sayfa, doğrudan kitabın kendi öznesine işaret etmekte, onu tutan parmaklar aracılığıyla da okuyucuyla kendisi arasına bir mesafe, bir katman koymaktadır. Ardından gelen "is an extension of the eye..." sayfasında ise okuyucunun baktığı sayfa, doğrudan gözünü okuyucuya dikmiştir; yani kitap okunan değil, bizzat okuyan özneye dönmüştür. 

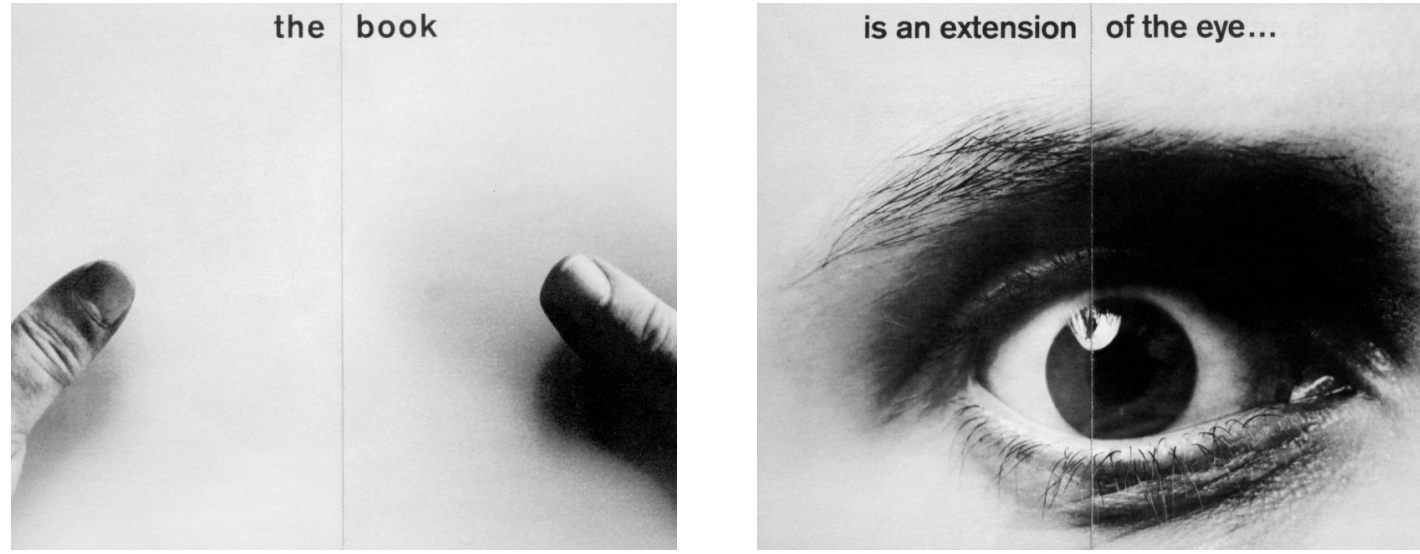

Görsel 4. The Medium is the Massage, "the book is an extension of the eye" cümleli ardışık sayfalar

The Medium is the Massage, yayımlandı ̆̆ı döneme bakıldığında yazar ve tasarımcı arasındaki birlikteliğin, metin ve imge arasındaki dengeyle örtüştüğ̈̈ ve tasarımcının kitabın yazarı ile eş konumda olduğu nadir örneklerindendir. Yayıncılık endüstrisinin yüksek kültür-halk, yazar-tasarımcı, metin-imge arasına keskin bir ayrım koyduğu dönemde bu kitap, yayıncılık hiyerarşisindeki keskin sınıflandırmaları bulanıklaştıran bir üretim sürecini teşkil etmektedir (Bilak, 2004).

\section{John Berger, Richard Hollis: Ways of Seeing}

İçlerinde İngiliz tasarımcı Richard Hollis'in de dahil olduğu, beş katılımcının bir ortak yazarlık çalışmasının ürünü olan Ways of Seeing, orijinali John Berger'in yazıp sunduğu ve BBC'de dört bölümlük bir televizyon programı serisinden uyarlanmış çok yazarlı bir kitaptır. Berger ve ekibi, televizyonun geçici olacağı düşüncesiyle, programın akıcılığını kaybetmeden aynı ruhu kitap sayfalarına taşıyarak kalıcı ve canlı bir kitap elde etmeyi denemişlerdir (Bilak, 2008)

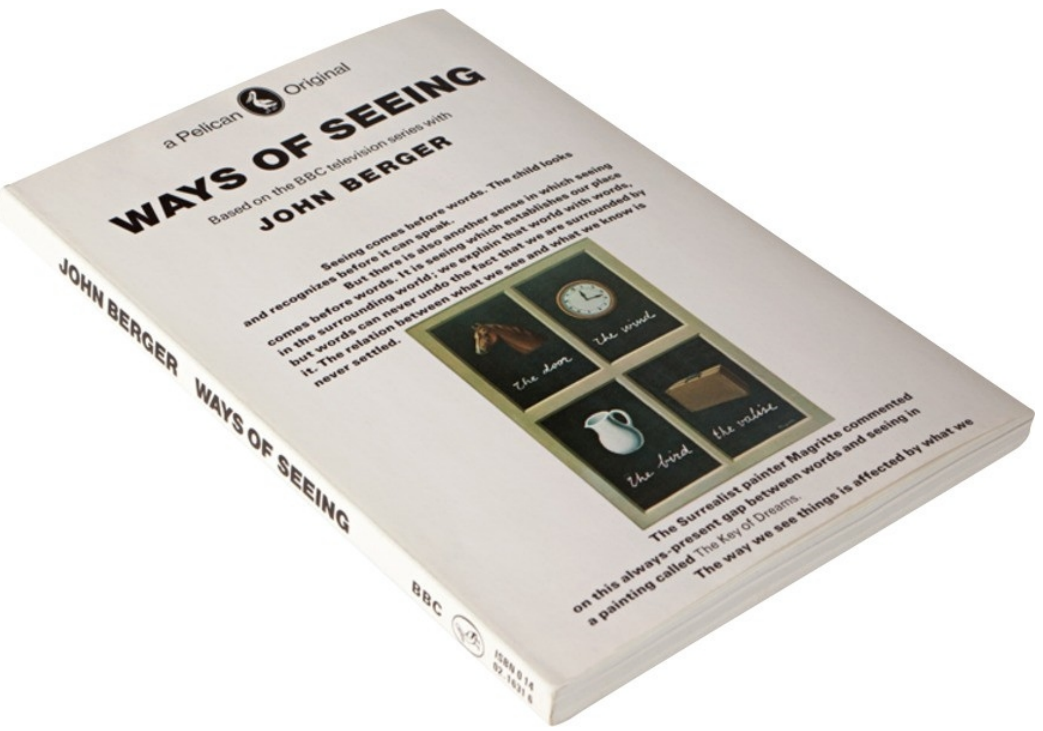

Görsel 5. The Ways of Seeing, 1972 yılında yayımlanan ilk baskısının kapağı

Kitap ve öncesindeki televizyon programı, 1400’lü y1llarda başlayıp 1900’lü yıllarda sona eren Avrupa sanat tarihi gelenekleri hakkında varsayımlar ve yorumlarda bulunmaktadır. Kitabın tüm anlatısı boyunca Berger, resimlerin kişisel anlatılarından çok insanların onları algılayış biçimlerini dikkate almıştır. Berger'e (1972) göre, insanlar bu resimleri, fotoğraf makineleri ve kameraların icadına bağlı olarak 20. yüzyılda, daha önce kimsenin görmediği biçimde görmektedir. Hollis de kitabı, Berger'in bu fikrinden yola çıkarak kurgulamıştır.

John Berger, kendisi ve tasarımcı Richard Hollis dışında üç kişiyi (Sven Bloomberg, Michael Dibb ve Chris Fox) daha ekibine almış ve hepsine kitapta eşit derecede yer vermiştir. Hollis'e göre yakın iş birliği kavramını vurgulamak için beş kişinin de rolleri belirsiz tanımlanmıştır (Bilak ve Bailey, 2005b). 1972 yılında BBC'de yayımlanan ilk bölümün girişinde Berger, programın içeriğinden bahsederken aslında kitabın bağlamına ilişkin tüm fikri de beraberinde vermektedir: 
Kameranın icadı, görme şeklimizle birlikte, yalnızca tek bir yerde, tek bir biçimde var olabilen resimleri yeniden üreterek onları farklı boylarda, farklı yerlerde farklı amaçlarda olabilecek şekilde değiştirmiştir. Resim, biricik olma amacıyla üretilir ve yalnızca asılı olduğu duvarda görülme imkânı vardır. Ancak 20. yüzyılda aynı resmi aynı anda birçok yerde görebilmekteyiz. İnsanlar artık bu sanat eserlerini kendi yaşam şartları dahilinde görürler ve o resimleri algılayış biçimimiz, sayısız dış faktörler ve kültürel yapılar tarafindan maniple edilmektedir (Berger, 1972, s. 5).

Ayrıca kitabın giriş bölümü de tasarlanma biçimi ve nedenini açıkça özetlemektedir:

Bu kitap beşimiz tarafından yapıldı. Televizyon serisi Ways of Seeing'in kapsadığı bazı fikirler bu kitap için başlangıç noktası oldu. Biz bu fikirleri açmaya ve irdelemeye çalıştık. Fikirler, yalnızca söylediklerimizi değil onları nasıl söyleyeceğimizi de etkiledi. İçerisinde taşıdığı çıkarımları ve savlarımızı başka biçimde düzenlenmiş bir kitapta sunamazdık. (...) Kitap yedi denemeden oluşmuştur. Bu denemeler istenen sırayla okunabilir. Denemelerin dördünde hem sözcükler hem de imgeler, üçünde yalnız imgeler kullanılmıştır. Yalnız resimlerden oluşan (kadınlara bakma biçimlerini ve yağlı boya resim geleneğinin çeșitli çelișik yanlarını inceleyen) bu denemeler, yazılı denemeler gibi seyirci-okurun kafasında soru uyandırmak amacıyla hazırlanmıştır (...) (Berger, 1972, s. 5).

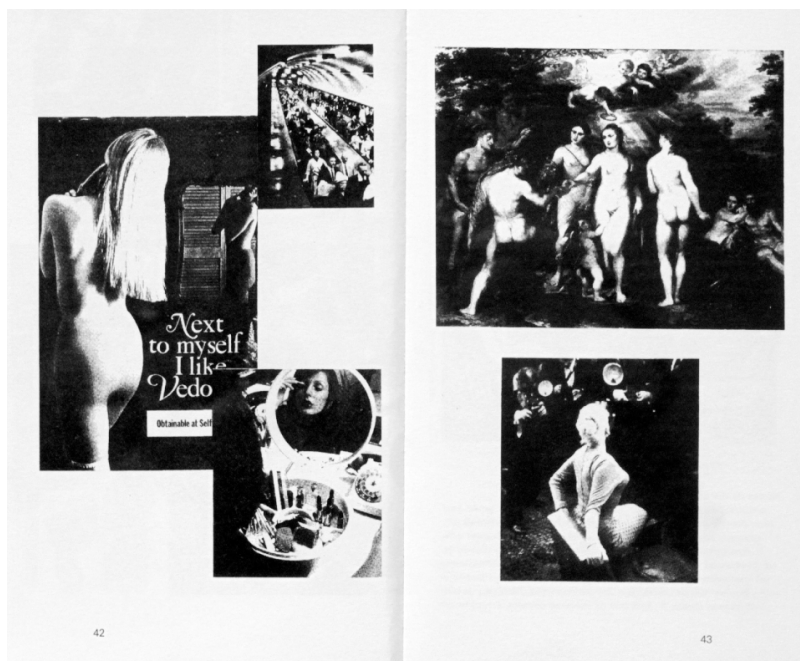

Görsel 6. The Ways of Seeing, kadın imgelerinin bulunduğu ikinci bölümden karşılıklı sayfa

Kitabın ulaşmaya çalıştığı nokta, yalnızca "okunan" bir aracı olması değil, aynı zamanda okurla etkileşime geçen bir anlatıcı gibi davranmasıdır. Richard Hollis de TV ve kitap arasındaki köprüyü doğru kurmak adına televizyon programındaki "ses ve görüntünün" kesişme noktalarını, kitabın doğrusal anlatısında "metin ve görsel"i birbirlerine sarılı biçimde devam ettirmiştir (Thompson ve Hollis, 2012). Hollis'in bizzat anlattığı üzere The Ways of Seeing kitabının alametifarikası olan bütünleşmiş metin ve görsel akışı, televizyon programında Berger’in yağlı boya tablolara eşlik eden sesli yorumlarına eşdeğerdir. Zaman zaman bir ses olmadan ekranda duran resimlerin kitaptaki karşılıkları ise yazı aralarındaki boşluklardır (Hollis, 2010 s. 49-63). TV programındaki sessizlik kitapta boş sayfalar ve satır aralarıyla karşılığına karşılık bulmaktadır

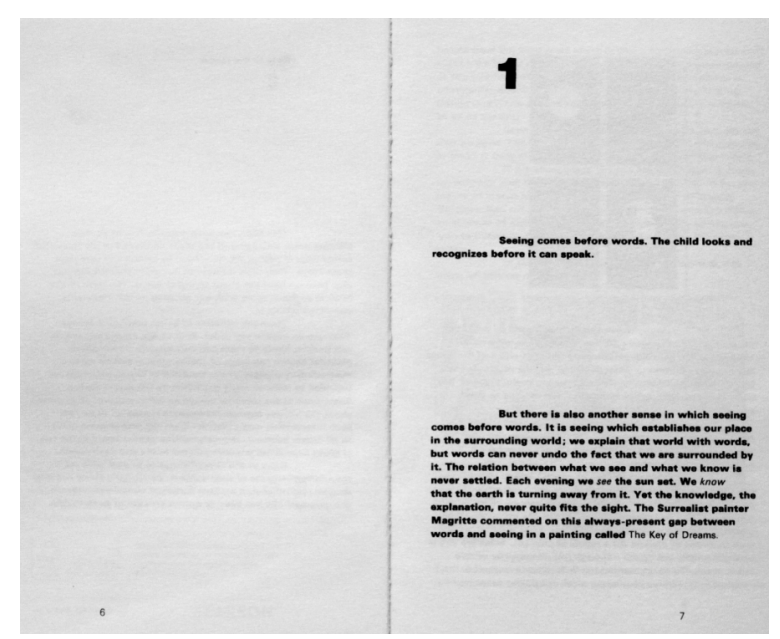

Görsel 7. The Ways of Seeing, birinci bölümün ilk sayfası 
Kitabın TV formatında Berger, arka plana resimleri alarak doğrudan seyircilere doğru konuşmaktadır. Programda gösterilen resimler, gösterilme süresi ve biçimleri ile Berger'in kurduğu diyalog, kitabın sayfalarında da benzer biçimi bulmuştur: "Görüntüler, diyalogsuz kelimeler gibidir" der Berger. Kitabın metinler ve resimler arası ilişkisi de bu diyalog fikrinden türemiştir. Seyirciye izletilen görüntüler ve anlamlar Berger tarafından düzenlenmişlerdir. Dolayısıyla kitapta okuyucuya gösterilen metin ve görseller de aynı düzenleme filtresinden geçmektedir. Bir nevi görsel "tercüme" olan bu girişim, Berger'in fikirlerinin netliği yok edilmeden kitap formatına çevrilmiştir (Bilak, 2008).

Highmore'a (2012) göre, kitabın çoksesli metni, kitapta Berger'in sesinin yansımasıdır. Bu ses, Berger'in sözlerini koyu ve vurgulu yazılmış olarak kendinden emin biçimde beyan etmektedir. Kitabın ilk sayfası gibi duran kapağı da kitabın yapılış biçimine atıfta bulunmaktadır: "Görmek, okumaktan önce gelir".

Metni resim, resmi metin gibi göstermek ve ikisi arasındaki görsel eşitliği korumak adına Hollis, Universe Bold yazı karakterini seçmiş ve metin-resim-altyazı ilişkisini kitap boyunca korumuştur. Görsel ve metin arasındaki biçimsel dengeyi devam ettirmek adına tüm resimler siyah beyaz basılmıştır (Hollis, 2013). Hollis bu tasarım kararıyla televizyon programında görüntüyü ve sesi aynı anda duyan izleyiciye aynı deneyimi kitapta da yaşatmayı amaçlamıştır.

Berger (1972): "Resmin asıl ve tek anlamı, tek güzelliği, orijinalinin bulunduğu yerde, kendisindedir. Resim, sessizdir." diye açıkladığı TV formatında resmin sessizlikte anlam kazandığını anlatmak için resimleri televizyon ekranında birkaç saniye boyunca hiç ses kullanmadan yansıtır. Ardından, algılayışımızdaki değişimi anlatmak adına aynı resmi bu sefer bir müzik aracılığıyla ekranda tutar. Hollis ise aynı deneyimi basit bir sayfa çevirme hareketiyle kitaba aktarmıştır; Van Goh'un bir resminin ayrıntısının altında "Bu, üzerinde kuşlar uçan bir mısır tarlası resmidir. Bir müddet bu resme bakın ve sayfayı çevirin" yazısı vardır. Ardındaki sayfada resim yeniden gösterilmekte ve altında el yazısıyla "Bu, Van Goh'un kendisini öldürmeden önce yaptığı son resimdir." yazmaktadır (Görsel 8). Hollis bu basit denemesiyle Berger' in kelimeler üzerindeki etkisinin imajlar üzerinde de uygulanabileceğini, hareketli TV görüntüsünde yakalanan etkinin kitabın sayfalarına da aktarılabileceğini göstermektedir.

El yazısıyla yazılmış olan bu mesaj, Berger'in yazıya dönüşmüş sesinden (yani kitabın kök metni için kullanılan yazı karakterinden) farklı bir biçimdedir. Bu notun hemen altından Berger, kendi sesiyle devam etmektedir: "Nasıl olduğunu tarif etmek mümkün olmasa da hiç şüphesiz kelimeler, imajın anlamını değiştirir. İmajlar da cümleleri anlatır".

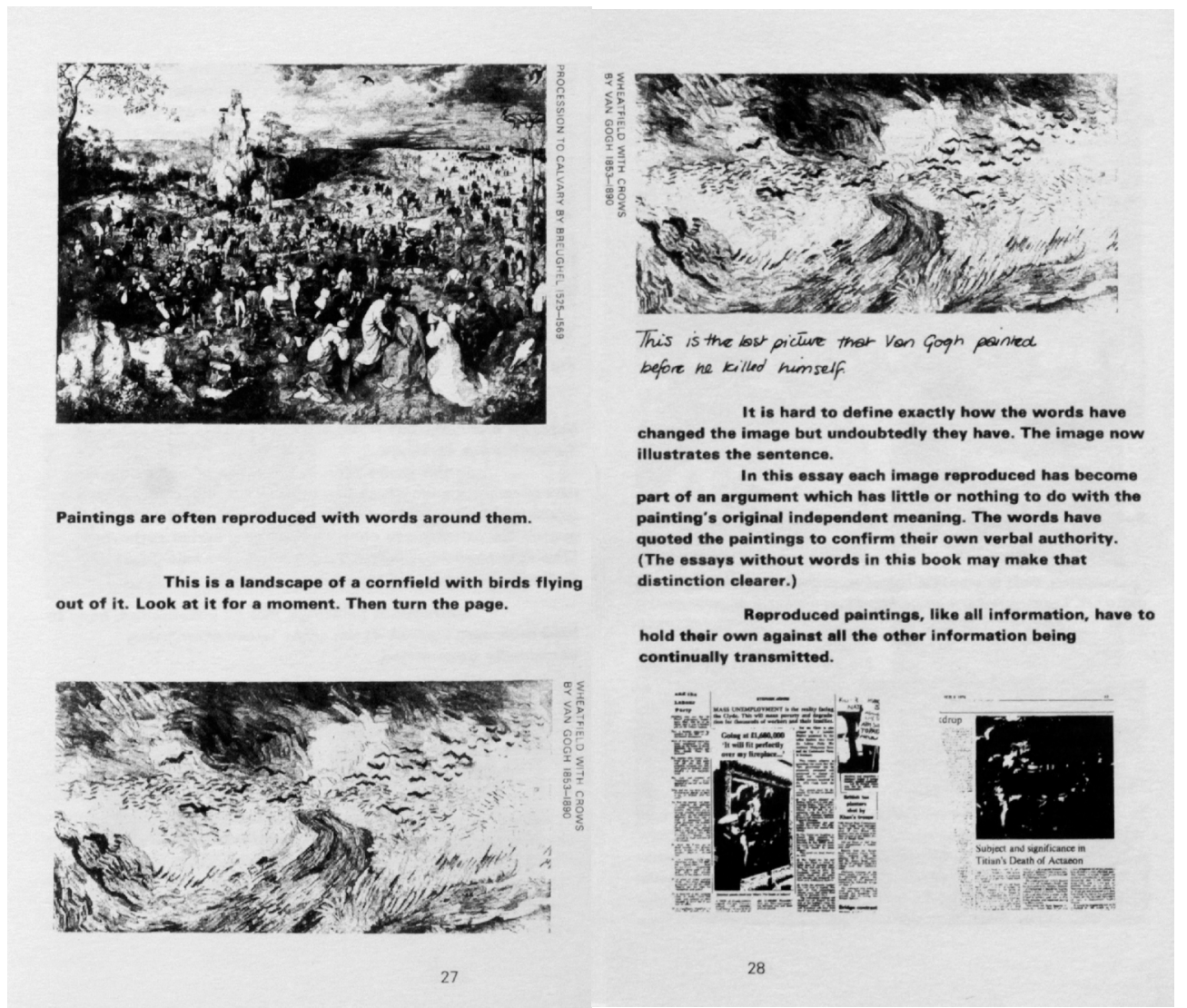

Görsel 8. The Ways of Seeing, Van Gogh'un resmimin iki farklı anlamda tekrar ettiği ardışık sayfalar 
İmge, metin ve boşluğun ahenkle tasarlandığı bu kitap okuyucunun algılarıyla doğrudan diyalog halindedir. Hatta bu diyalog, kitap bittiğinde yeni başlamaktadır; indeks bölümünün ardından gelen ve son sayfa yazan "to be continued by the reader" ifadesi, açılışındaki "bu kitabı beşimiz yaptık" ibaresine atıfta bulunarak kitabın oluşum sürecine altıncı katılımcı yazarı da dahil edilmiştir: "Okuyucu".

\section{Ferit Edgü, Bülent Erkmen: Kitap}

“(...) Kendinden başka bir mesajı olmayan bir kitap kurduk ve bir kitabın oluşum sürecindeki yazar-tasarımcı iş birliğini tersine çevirdik. Ben, Edgü’nün metnini yorumlayarak bir sayfa düzeni yapmayacak, tersine, Ferit Edgü benim taslağımdan esinlenen bir metin yazacaktı." (Erkmen, 2007).

Kitap, 1989 yılında tasarımcı Bülent Erkmen ve yazar Ferit Edgü tarafından düşünülüp yapılan, Türkiye'de pek de benzerine rastlanmamış ortak yazarlı bir kitap çalışmasıdır. Ofset Yapımevi iş birliği ile sınırlı sayıda basılan ve satış dışı tutulan bu özel kitap hakkında ise çok az kaynak bulunmaktadır.

Önceden karar verilmiş bir metin ve görsel olmaksızın, "bütünden özneye" diye nitelendirilebilecek bir yöntemle; bir kitap yazma ve tasarlama sürecinin tam tersi olarak düşünülen Kitap'ta Erkmen, öncelikle sayfa sayısı, boyutu ve cildi gibi kitabın fiziksel özellikleriyle birlikte sayfalarda yer alacak metnin kelime sayısı, büyüklüğü, sayfalara olan dağılımı, ayrıca sonradan seçilecek olan görsel için yerleşimleri ve tekrarları da hesaba katarak, bir nevi "içeriksiz olarak içerik" üreterek bir taslak hazırlamış ve bu taslağı yazılmış bir kitaba dönüştürmesi için Ferit Edgü’ye teslim etmiştir. Edgü ise Erkmen'in hazırladığı taslağa sadık kalarak, onun istediği kelime sayısına uygun bir metin yazmış ve görüntüler için de Firdevsi’nin Şehnamesi isimli minyatürü seçmiştir. Kitabın son sayfasında orijinal dia boyutunda kullanılan bu minyatür (Görsel 9), kitap boyunca kadrajlar alınarak, büyütülerek ve parçalanarak tekrar tekrar kullanılmıştır.

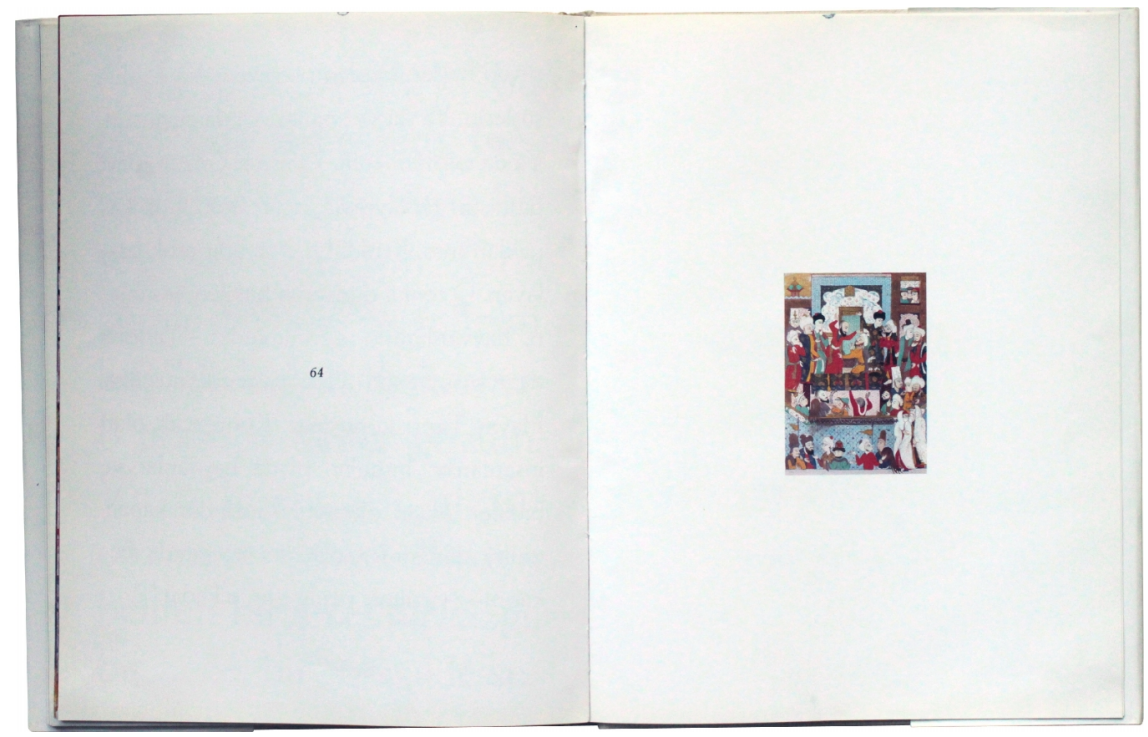

Görsel 9. Kitap, sayfa numarası ve kitabın son sayfasında yer alan minyatürün bütünü

Tasarımcısının, yazılmadan önce tasarladığı, yazarının tasarlandıktan sonra yazdı̆̆ı bu çalışma, kitabın bir anlamda "kendi ile başlayıp kendinde son bulması" olarak nitelendirilebilir. Ana akım kitapların hazırlanma sürecinde önce bir metin vardır, sonra o metin bir tasarımcı aracılığıyla kitabın içerisine girerek nesneleşir. Kitabın nesnesi, metinden önce yoktur. Metin yazıldıktan sonra kitap düşünülür. Ancak bu örnekte süreç tersine işlemiştir. Sonradan yazılacak bir metin ve bulunacak bir görsel için Kitap, içeriksiz tasarlanmıştır. Üstelik yazılan metin ve kullanılan görsel de Kitap boyunca kitabın nesnesine işaret etmektedir. Bir sayfada yer alan detay imge, kimi zaman tek başına bir anlatıyı oluşturmakta, kimi zaman ise bir sonraki sayfanın habercisi ve tamamlayıcısı görevini üstlenmektedir. Minyatürdeki suretler (Görsel 10), yer aldıkları düzlemden koparılıp tek başlarına kullanılarak birbirleriyle ilişki içerisine girmiştir (Karol, 2012). Dolayısıyla kitabın görünür öznesi bir minyatür, gerçek öznesi ise kitabın kendisi olmuştur. Bu bağlamda Köksal'ın (1994) deyişiyle Ferit Edgü tarafindan yazılan metin yerine başka bir metin parçası, minyatürün yerine de herhangi bir resim koyulsa bile kitabın bildirisi değişmemektedir. 

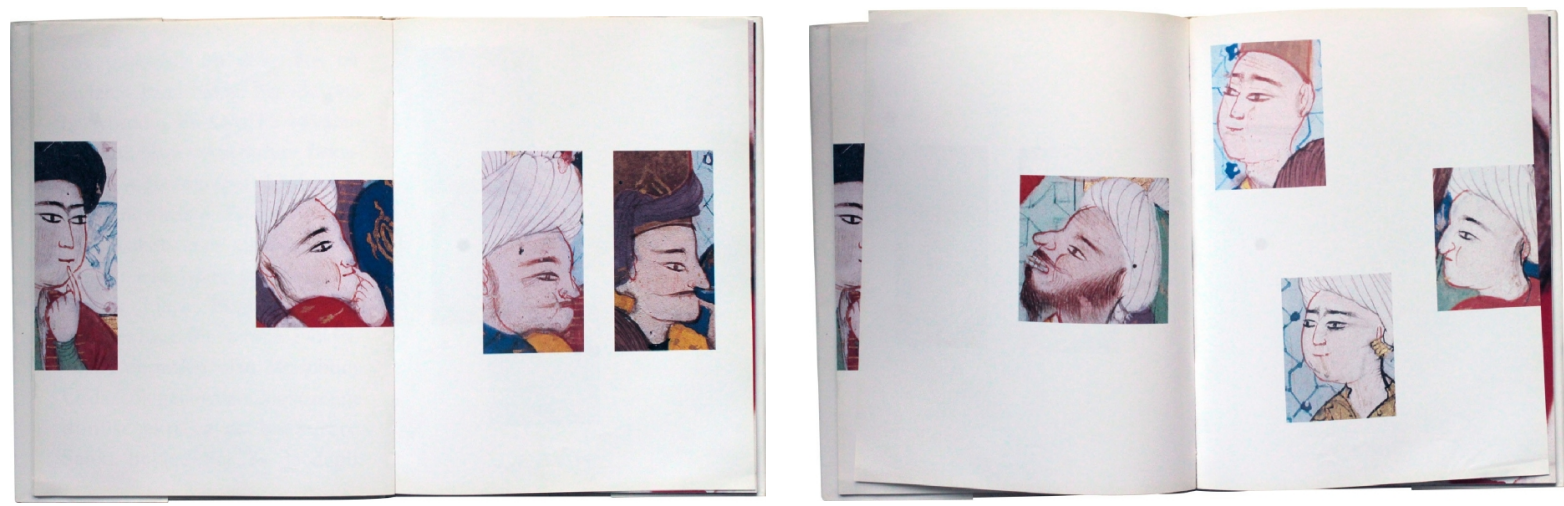

Görsel 10. Kitap, minyatürden alınan kadrajlardan ardışık sayfalarla oluşturulmuş bir anlatı

Metnin sonradan yazıldığı bu kitapta, yazılmamış bir yazı olarak hazırlanan kör metin, Ferit Edgü tarafından gerçek metin halinde getirilip bir bakıma Türkçeleştirilmiştir. Yani metin, resim olan bir yazı yerine geçmiştir. Bir kitap tasarımında temel doğru olarak kabul edilen metinle resim arasındaki ilişkinin önceden kurulma hali, bu kitapta geçerli değildir. Kitaptaki yazıya, imgeye davranıldığı gibi davranılmış; kör metinde yer alan anlamsız kelimeler bütünündeki yapı, gerçek metin yazılırken aynen korunmuştur. Erkmen'in de ifade ettiği gibi Kitap, içeriksiz metinle içerikli görsel arasındaki ilişkiye dönüşmüştür (Karol, 2012).

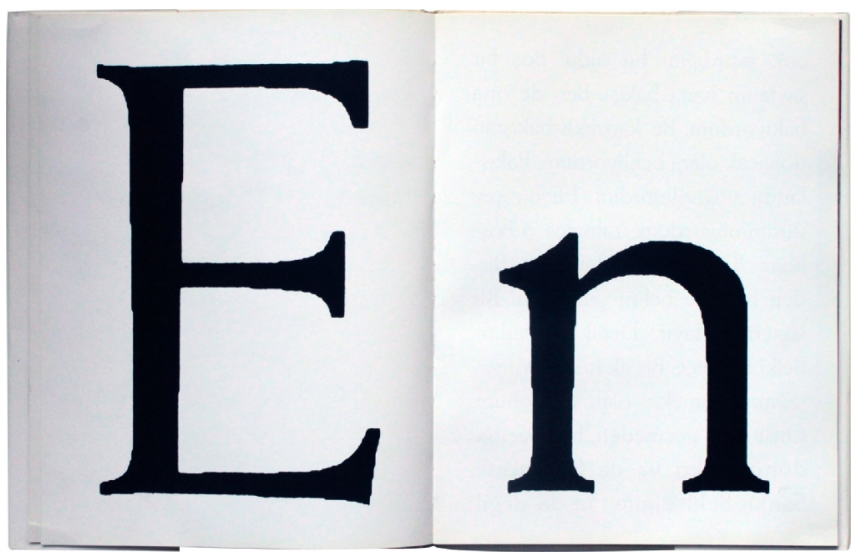

Görsel 11. Kitap, yalnızca iki harfin yer aldığı, imgeye dönüşmüş bir kelime

Ferit Edgü, yazım biçimi olarak projenin sürecini de açığa çıkartan bir tavırla kitabın kendi kendisini anlatmasını tercih etmiştir. Kitaptan: “...kalan yalnızca bir söz ve cük oluyordu. Ya da bir çiz ve gi oluyordu. Ya da bir ren ve ek oluyordu. Ya da bir sur ve et. Böylece tümü kavrayamayan insanoğlu (ben) parçaları kavramaya, onlardan bir bütün yaratmaya çalışıyordum...” (Edgü ve Erkmen, 1989, s. 53)“...orda, çok geçmeden bir sözcüğe dönüşecekti ya da bir surete...” (Edgü ve Erkmen, 1989, s. 20) “...ola ki bu suretlerden biri de bendim. Ya da renklerden ya da sözcüklerden...” (Edgü ve Erkmen, 1989, s. 30).

çok şaşırdığım bu oldu. Boş bir sayfanın bana bakışı. Ben de ona bakıyordum. Bu karşıııklı bakıştan doğacak olanı bekliyordum. Bakışlarımı yoğunlaştırdım. Hiçbir şey düşünmüyordum. Yalnızca o boșluğu. Bakışlarımın algıladığı. Birden bir leke belirir gibi oldu. Bir sözcük. Hayır. Değil. Bekledim. Belki bir hece. Bir ilk hece. Döl yatağına düşmekte olan bir tohum. Orda, çok geçmeden, bir sözcüğe dönüşecekti ya da bir surete. Sanki. Beklediğim. Ya da değil.

Görsel 12. Kitap, Ferit Edgü’nün metni ve bir sonraki sayfanın habercisi olan sağ sayfa 

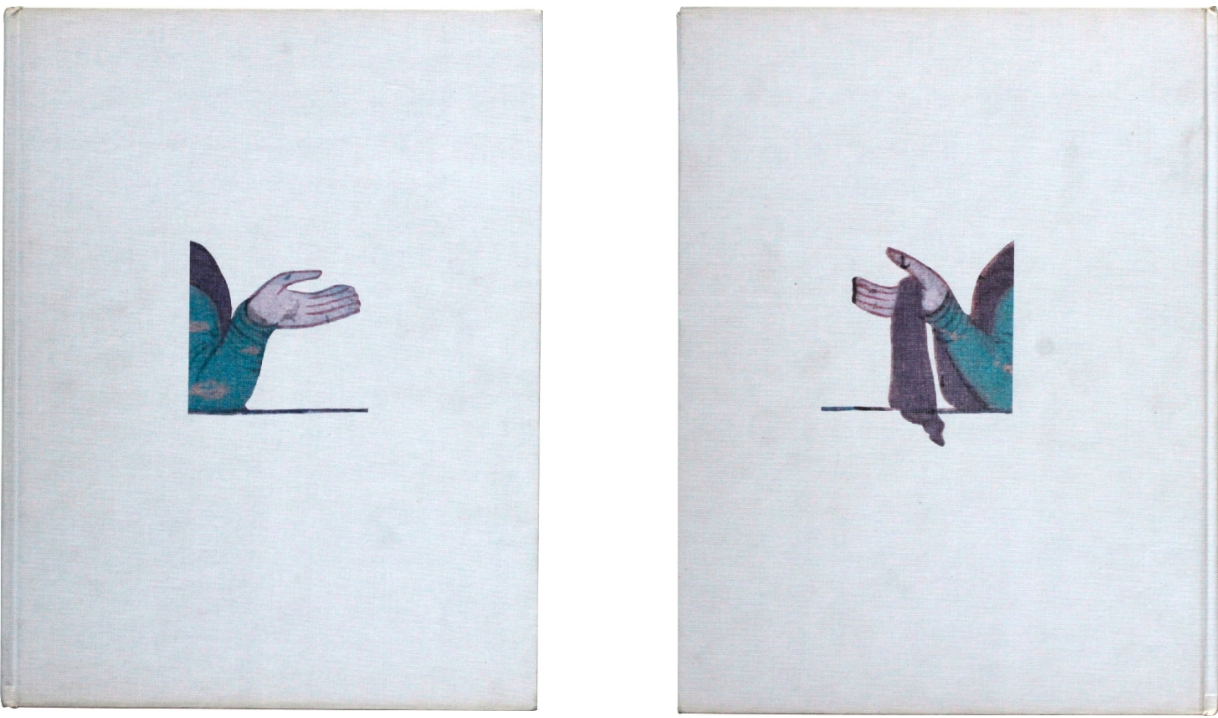

Görsel 13. Kitap’ın Ön ve arka kapağı

Kitapta özneleşen bir diğer tasarım malzemesi olan sayfa numaraları, boş bir sayfanın varlığını belirtmek için tam ortada kullanılmıştır ve tüm sayfayı kapsayan, sayfayı tanımlayan bir öğedir. Görsel veya metin olan sayfalarda ise numara kullanılmamıştır. Kapağı sararak bütünü tamamlayan şömiz, sonrasını ve öncesini işaretleyen kapak içi sayfalardaki delikler, ön kapakta kitaba davet eden ve arka kapakta da veda eden el imgeleri (Görsel 13), tasarımın üçüncü boyuta dek ulaşan olanaklarıyla kitabın nesnesine işaret etmektedir. Köksal'a (1994) göre kitap tasarımının içerdiği tüm bilgi, kitabı, "tasarımın kendisiyle" özdeş konuma taşımaktadır; yani kitap, içinde taşıdığ 1 ile birlikte, aynı zamanda kendisini de taşımaktadır. Bu yüzden kitap, ismini kendi nesnesinden ödünç almıştır: Kitap.

\section{Sevim Burak, Bülent Erkmen: Yanık Saraylar}

Sevim Burak'ın Yanık Saraylar, Everest My Lord, İşte Baş İşte Gövde İşte Kanatlar gibi tüm yapıtlarının olduğu dizinin üçüncü basımı, 1993 yılında Nisan Yayınları tarafından yapılmış ve Bülent Erkmen tarafından yeniden tasarlanmıştır. Yanık Saraylar'ın, ilk basımı bir yayınevi olmadan 1965 yılında, ikinci basımı da Adam Yayıncılık tarafından 1983 yılında yapılmıştır. İlk iki basımda sayfa dizgisi, Sevim Burak’ın daktilosunda yazdığ şekilde, müdahale edilmeden basılmıştır (Köksal, 2010).

Bülent Erkmen, 1993 yılı yayımlanan baskısında ise kendisini Sevim Burak yerine koyup, yani söz gelimi “yazar” gibi davranıp önceki baskılarından ayrı olarak orijinal metinlerin biçimsel düzenlemelerinden kitabın kapak ve boyutuna kadar müdahalede bulunmuştur. Kitabın bu yeni yorumu, tartışmaları da beraberinde getirmiştir: Yayınevinin kurumsal dizgisiyle veya bir metnin orijinal biçimde basılan dizi ile bir tasarımcının müdahalesiyle basılanlar arasındaki biçimsel yorum farkı, metnin anlamında da farklılıklar yaratır mı? Metnin okuma biçiminin değişmesi, anlamını da değiștirir mi? Tasarımcı, önceden yazılmış ve basılmış bir metni; içeriğini değiştirmeden yalnızca yazılış biçimine dair yeni bir tasarım önerisi getirdiğinde, tasarımcıyı eser sahibi kadar metnin sahibi ve ortak yazarı yapar mi?

Sevim Burak'ın yazılarındaki anlam-biçim ilişkisi, Erkmen'in tasarım üslubuyla edebiyat dünyasında yeniden tartışılmaya açılmıştır. Sevim Burak yöntem olarak metinlerini onların biçimsel görüşüşlerini de planlayarak oluşturan bir yazardır. Bu yüzden yayımlanmış tüm kitaplarındaki sayfa dizgisi, Burak'ın orijinal dizgisine sadık kalınarak hazırlanır. "Öz’ü, tam bir yalınlıkla ortaya koyabilmek için, bende, biçimsel çabanın ileri gitmesi gerekir" ifadesiyle Sevim Burak, kendi yazım üslubunun biçimsel yorumlamadan kopmayacağını dile getirir (Güngörmüş, 2003, s. 36). Ancak Nisan Yayınları serisinde Burak'ın bu öz-metin yapısı, -cesur bir denemeyleErkmen'in öz-tasarım yapısına dönüşmüştür.

Yazı, soyutlanmış kavramları bir anlatıya, bir gösterge dönüştürmek için malzeme olarak yine kendisini kullanmaktadır. Sanatın en genel tanımıyla bu, imgenin bir simgeye dönüşmesi olarak yorumlanabilir. Bu bağlamda Sevim Burak'ın özü yakalayabilmesi için onun belli bir biçimini kullanması gerekmektedir ve bu biçim de kelimelerdir. Sevim Burak, "İnsanın özü herhangi bir soyutlamayla aktarılabilecekse elbette bir kelime kaldırılıp onun yerine bir işaret de koyulabilir" der (Güngörmüş, 2003, s. 36). Burak’ın öz arayışı bir sanatsal dışadönüklük olarak değerlendirilebilir ve kelimelerin nasıl bir araya geldiği (veya getirildiği) Sevim Burak'ın eserlerinde aynı zamanda biçimsel bir meseledir. 
Sevim Burak için kelimeler, birer işarettir. Herhangi bir kelime yerine bir eşya, çizim, fotoğraf veya bir işaret koyabilir ve özü anlatabildiği sürece kelimeler de birer nesnedir. Dolayısıyla kitaplarında metinlerle birlikte biçim ve görsellik de aynı derecede önem taşımaktadır. Bir yazıyı veya kelimeyi düz yazmak, onu parçalamak kadar anlam-biçim ilişkisiyle ilgili bir meseledir. Güngörmüş'e (2003) göre, Sevim Burak metinlerini, herhangi bir düz yazıdan ayıran, kelimelerin anlamlarıyla onların yazılış biçimleri ayrılmaz bir bütün oluşudur.

Bülent Erkmen, Nisan Yayınları serisinde kurduğu metin-kitap ilişkisiyle kitabın önceki baskılarında alınan kararları tekrar etmek yerine, kitabı kitap yapan tüm öğelerin işlevlerini sorgulayarak Sevim Burak'ın biçimsel yazısına yeni bir biçimsel yorum getirmiştir.

Erkmen bu yeniden yorumlama girişimini, yani yayımlanmış bir kitabın yeni baskısının tasarlanması işini tıpkı bir klasik müzik eserinin çağdaş yorumlaması, 50'lerde çekilmiş bir fillmin bugünde tekrar uyarlanması veya bir tiyatro oyununun yeniden sahnelenmesi gibi gördüğünü belirtmektedir: "Bir kitabın yeni basımı, sadece kapak tasarımı yeni olan bir kitap demek değildir. Bir kitabın yeni basımı, kitabın ilk baskısının tıpkıbasımı demek değildir. Yeni basım, yeni yorumdur. Yeni yorum, kitabın, yazarın nefesidir. Yeni yorum, kitabın yeniden kitap olmasidır" (Erkmen, 1994, s. 5).

Erkmen, Burak'ın yazma süreciyle ilgili şu anekdotu dile getirmektedir: "Sevim Burak metinlerini odasındaki perdelere iğneleyerek oluştururdu. Tüm metinlerini bir arada görüp, ekleme ve çıkarmaları, kısaca kurgusunu perde üzerinden yapardı" (1994, s. 5). Erkmen kitabın kapağını da Burak'ın bu yazım sürecine eșlik eder bir fikirle tasarlamıştır. Kitap, üst üste kapanan çift kapaktan oluşmaktadır. İlk kapakta toplu iğne simgesi, ikinci kapakta ise her kitapta değişen perde deseni kullanılmıştır (Görsel 14).

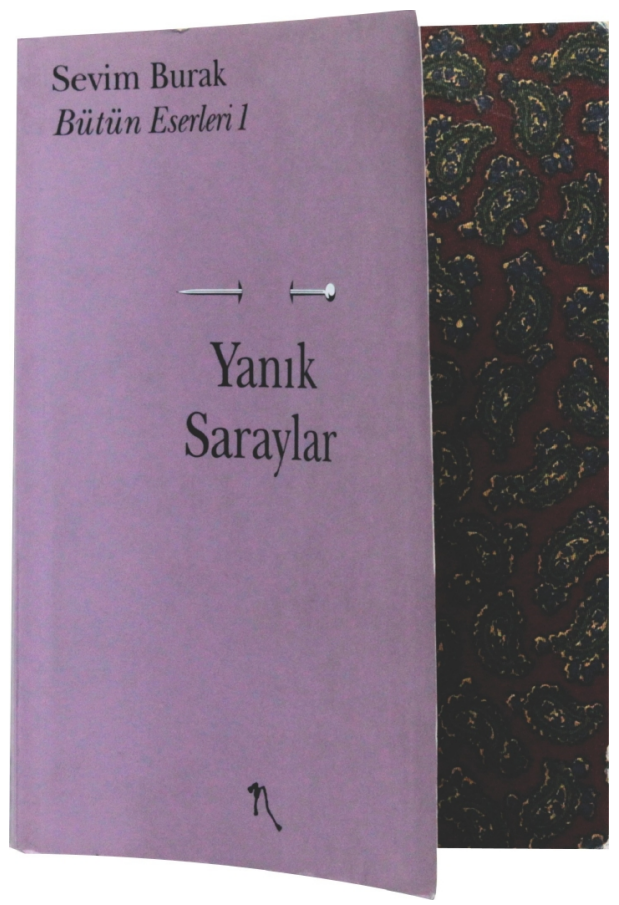

Görsel 14. Yanık Saraylar, toplu iğne ve başlığın bulunduğu ilk kapak ile perde deseninin kapladığı ikinci kapak

Tüm seriyi işaret eden bu kapak kimliğinin devamında, özellikle Yanık Saraylar'da daha da dikkat çeken bir unsur olan tipografik müdahaleler göze çarpar. Erkmen (1994), Burak'ın daktiloyla düzenlediği kelime-satır-paragraf oyunlarına tipografik normlar içerisinde yeni bir yaklaşım sergilemiş, Burak'ın satır kaydırmalarını, yazı blokunun başlangıcına; sıfır noktasına çekmiştir. Burak ayrıca yazılarındaki "ses"leri daktilonun mekanik sınırları içerisinde vurgular. Bunu da bazı harfleri büyük harfe yazarak sağlar. "Temel yapısı küçük harf olan bir kelimenin haykırmayı vurgulamak için büyük harfle yazılması, sesi yeterince görünür kılmamaktadır" der (s. 5). Erkmen bu haykırışı, Sevim Burak’ın sesinin daha iyi duyulduğunu düşünerek, aynı kelimenin küçük harflerini bu kitapta büyüterek göstermeyi tercih etmiştir (Görsel 15). 


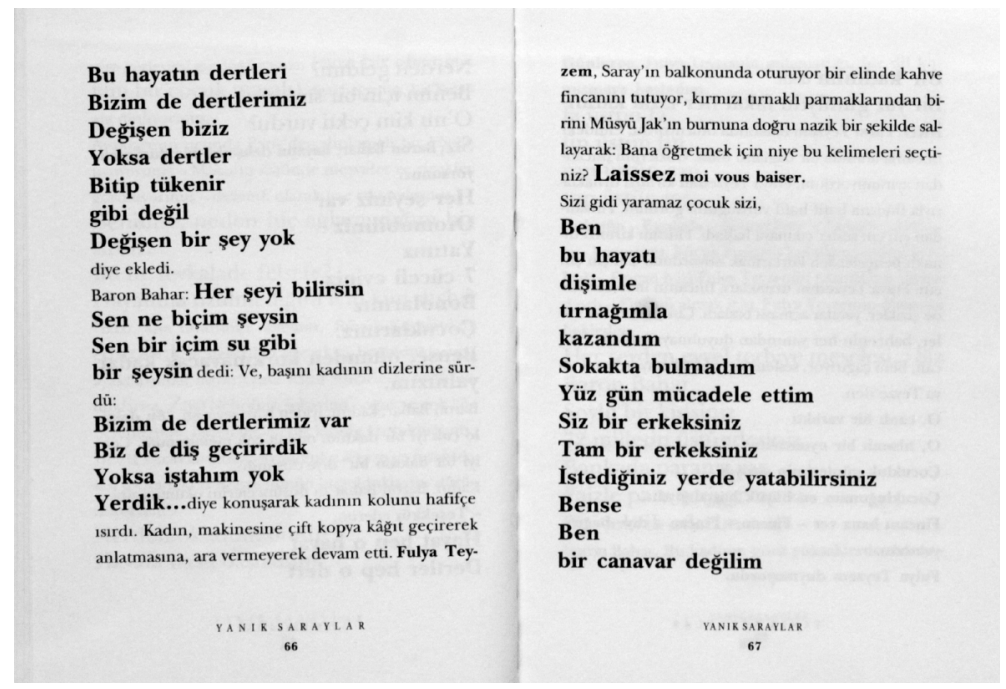

Görsel 15. Yanık Saraylar, Erkmen'in tipografik müdahalelerinin görüldüğü karşılıklı sayfa

Kitabın bir diğer görsel öğesi, Burak'ın metinlerinin sonunda yer alan Sarkis'in kendisinin çekip yaktığı fotoğraflardır. Kitabın ikinci basımında sayfanın ortasına, kenarlarda sayfa boşlukları kalacak şekilde yerleştirilen fotoğraflar, Bülent Erkmen'in tasarımında her hikâyenin başında, yalnızca sol sayfalarda yer almaktadır. Siyah beyaz olan fotoğraflardan tam etki alınabilmesi için dört renk ayrımlı siyah beyaz basılmış ve bu sefer tüm sayfayı kaplayacak şekilde yerleştirilmiştir. Yanan fotoğrafların altından ise kitabın basıldığı kâğıdın kendisi görünmekte; sayfanın kendisi, fotoğraf öznesine dönüşmektedir (Görsel 16) (Erkmen, 2007).
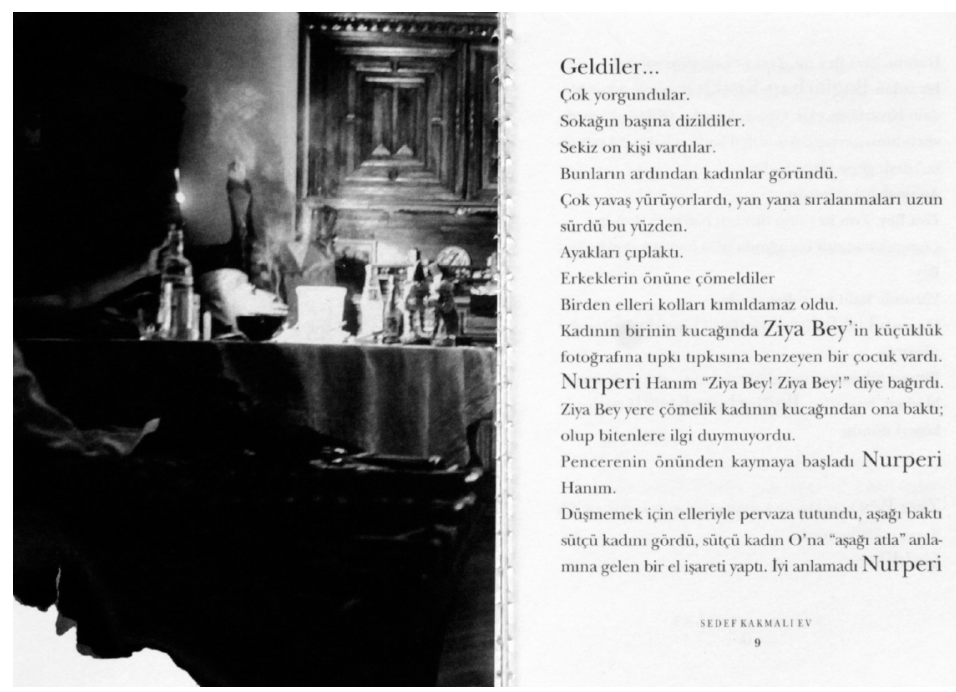

Görsel 16. Yanık Saraylar, Sarkis'in fotoğrafının bulunduğu sayfalardan bir örnek

Kitabın basıldığı yıl Bülent Erkmen'in bu tasarım yorumu üzerine Memet Fuat, Semih Gümüş ve Enis Batur'un dahil olduğu bir tartışma başlamıştır.

Fuat'a (1994) göre “yazar”; arada bir kişiye ihtiyaç duymaksızın okuyucuyla iletişime geçebilmektedir. Bu yüzden tasarımcı, yazarın izni olmadan, bir kitabın metniyle kesinlikle oynama hakkına sahip değildir. Tasarımcı, yazarın sorumluluğunu üstlenmemelidir. Fuat, Erkmen'in müdahalesine; "yaptıkları işin biçimlendirişiyle kitap tasarımcıları yazın adamlarına dönüşürdü" yorumunda bulunmuş̧ur (s. 11).

Enis Batur'a göre ise tasarımcı, bir metni kitaba dönüştürürken, kitabın "biçiminin" seçilmesinde kuşkusuz ki pay sahibidir. Ancak Sevim Burak gibi yazar veya şairler kendi yapıtını kurarken metne çoğu zaman "tasarım düzeyinde" yaklaşmaktadır. Batur şöyle der:

Yazının sayfadaki konumu, yazının boyutu ve metnin genel akışı yazarı tarafından matematiksel duyarlılıkla ele alınmaktadır. Böylesi yazarların yapıtları kitaplaştııılırken tasarımcının yoruma dayalı müdahalesine gerek yoktur. Yazarın kurduğu düzen, kitapta biçimsel leke olarak da okunmaktadır. Metne ve bütününde kitaba yapılan yeni müdahalenin eserin anlatım diline, ana fikrine ve yazılış hikayesine ait 
yeni okuma önerileri getirmesi gerekmektedir. Çünkü metin; birbirleri ardına gelen sayfalar içerisinde, herhangi bir sayfaya, herhangi biçimde konmuş bir yazı yığınından çok, metnin anlamını betimleyen biçimsel anlamların yarattığ 1 bir tasarım derdine dönüşmüştür. Bu noktada okuyucu, Bülent Erkmen'in Sevim Burak yorumu yerine, Sevim Burak'ın kitabını, onun değişmeyen içeriğini seçmektedir (Batur, 1994, s. 20-22)

Tüm bu tartışmalar, temelinde tasarım kararlarının, okunacak metnin anlamını ne kadar değiştirdiğine de dikkat çekmekte, anlam değişikliğinin ise yazar ile okuyucu arasına giren bir engel olabileceğini öne sürmektedir. Özellikle Yanık Saraylar örneğinde bu değişiklik, Sevim Burak'ın iç dinamiğini de çarpıtacak bir anlam soyutlamasına doğru gitmektedir. Gümüş'e (1994) göre;

Yazınsal metnin yapısal dokusu, verilmiș bir içerik ve biçimle birlikte var olur ama, bunun da değișmez bir yapısı olduğu düşünülemez (...) Zaman içinde değişen yazınsal kültürün doğurduğu yeni okuma biçimleri, başlangıçta verilmiş anlamı eskitebileceği gibi, yeni anlamlarla o metni zenginleştirecek katkılar da yapabilir (...) Bir yorum söz konusu ediliyorsa eğer, yazınsal metinlerde ortaya çıkan anlam boşluklarına karşılıklar bulma çabasının okuma edimi üstündeki zoru yüzündendir. Tasarımcı ise, böyle bir boşluk bulma çabasını ancak kendisi de bir eleştirmen-okur olduğunda yapabilir; yoksa dış biçimine karışarak yapacağı içerik bozmalarıyla boşluklar doldurma yetkisini, herhalde tanrısal bir yetkeyle alabilir bir tasarımc1. (s. 38)

Köksal (2010) ise, tartışmayı tasarımcının lehine bir taraftan ele alır: "Metnin sahibi olan yazarın ötesinde; eğer bir tasarım üretimi sanatsal üretim olarak tanımlanacaksa, işin içeriğinden doğan tasarımın tek yaratıcısı tasarımcısıdır" der. Yani bir yazın-yapıtı tasarım yapıtına dönüştüren (metni tasarıma dönüştüren) kişi onu tasarlayarak yeniden yazmış, dolayısıyla metnin yeni yazarı, müellifi olmuştur.

Kuşkusuz ki Erkmen'in yorumu, metnin gerçekliğini değiștiren, dışarıdan bir müdahaledir. Yani yeniden yorumlanmış bir yazıdır. Metnin sayfa düzeninde yer alma biçimi, yazının anlatımının bir parçasına dönüşüyorsa eğer, bu dönüşümün yegâne sorumlusu olan ve her müdahaledeki bilincin farkında olan tasarımcı da Köksal'ın bakış açısıyla, yazarla birlikte yapıtın sahibi olmaktadır.

\section{Rem Koolhaas, Bruce Mau: S, M, L, XL}

"Bir tasarımcının, tasarladığı bir kitabın kapağına "yazar” olarak yer alması, author kelimesinin otorite karşılığına denk düşen bir yaklaşım sayılmaktadır. Kapakta yer alan isim, otoritenin imzası, bir mührüdür.” (Lupton, 2009).

The Medium is the Massage örneğinde gördüğümüz, tasarımcının adının kapakta yazar ile birlikte yer alıyor oluşunun ikinci ve en popüler örneği, Rem Koolhaas ve Bruce Mau ortak yapımı olan S, M, L, XL kitabıdır. 90'lı yıllarla birlikte içeriğin tasarımla formüle edilmesi gerektiğini düşünmeye başlayan tasarımcılardan birisi olan Mau işlerinde, içeriğin tasarım pratiğinin dışında bırakılmak zorunda olmadığını beyan eder. Esas amaç, tasarımı, geliştirilen içeriğin üzerine kurmaktır. Mau, tasarımcının kendi araştırmalarını, yorumlarını ve bakış açısını kabul ettirebilen bir eş yazar olma hakkını savunmuş, tüm ana hatların belirlendiği, içeriğe dair tüm kararların verildiği noktadan sonra tasarımcının davet edildiği bir tasarım sürecini reddetmiştir (Novosedlik, 1994).

Bruce Mau, S, M, L, XL dışında, Life Style, Massive Change ve Zone serisi kitaplarında da "tasarımcının yeni rolünü yeniden düşünmek" üstüne fikirlerini sunmuştur. Mau için müellif tasarımcının ortaya çıkardığı tasarım ürünü, dünya ile bütünleşik bir öz ve somut biçimin birleşimi; içerik ve tasarımın kesişim noktasıdır. Edebiyat, özgür bir üretim dürtüsüyle meydana gelmektedir. Ancak tasarım, bir üretim talebinin sonucu olduğu için böyle bir özgürlük lüksüne sahip değildir. İşte bu noktada Mau için müelliflik, içeriği ve problemi şeffaflaştıran yazar ile görsel iletişimi kuran tasarımcının bir araya gelmesidir: "Biz tasarımcılar, yaşam için zorunlu olarak ürettiğimiz tasarım nesnelerinin sahip olduğu 'bağlamı' açık bir şekilde telaffuz etmeliyiz” diyen Heller ve Mau'ya (2000) göre tasarımın içsel bağlamını üretme pratiğinin merkezine alan müellif tasarımcı hem üretici, hem de ürettiği nesnenin eleştirmeni olmak zorundadır. Çünkü görsel kültür çağında imaj üreten bir tasarımcı, içerik sorumluluğunun bir parçası olarak kabul edilmektedir.

Tüm bu meselenin odaklandığı ve tasarım mesleği tutkusunu en iştahlı biçimde beyan eden S, M, L, XL adlı büyük kitap, kapakta adları eşit şartlarda yer alan Bruce Mau ve mimar Rem Koolhaas'1n 90'lar döneminde yaratmış olduğu tasarımsal bir devrim olarak kabul edilir (Poynor, 2000). Yaklaşık 1.400 sayfası ile ortalama bir ansiklopedi genişliğine sahip olan S, M, L, XL okuyucunun eline aldığında karşılaşacağı sıradan bir kitaptan daha ağır ve kompleks bir yapıya sahiptir. Rem Koolhaas ve şirketi OMA hakkında bilindik bir biyografi olarak başlayan bu proje, Mau'nun deyimiyle "mimarlık hakkında bir çeşit roman”a dönüşmüş, Rem Koolhaas çalışmaları ile mimarlık pratiğinin gizli sürecini ortaya koyan; başlı başına bir "iş" olmuştur (Karol ve Tanyeli, 2007). Achten'e (2014) göre ise bu iş, biçimsel üretim yöntemi göz önünde bulundurulduğunda yalnızca "yazılanın" değil, "görünenin" de bir romanıdır. 


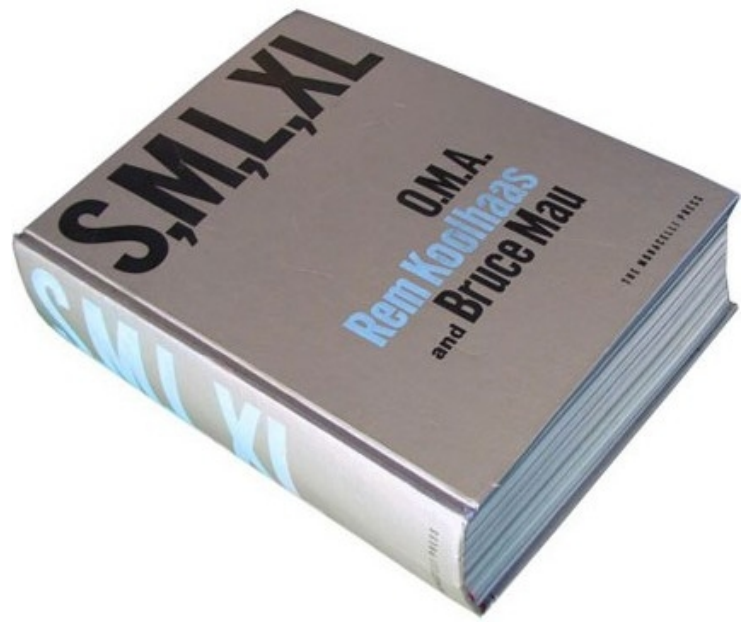

Görsel 17. S, M, L, XL kapak tasarımı

S, M, L, XL'nin arka kapağından:

S, M, L, XL, melez bir ortak yazarlık ürünüdür. Kitap, Rem Koolhaas'ın yazıları ve Bruce Mau'nun biçimlendirdiği sekanslardan oluşmaktadır (...) Bu cüsseli kitap, mimarlık hakkında bir romandır. Rem Koolhaas ve Bruce Mau tarafindan düşünülüp tasarlanmıştır (...) (Koolhaas ve Mau, 1995).

İçeriğin, kilit kararlar alınıp yazılar hazırlandıktan sonra tasarımcıya teslim edilmesi geleneğinden farklı olarak Mau, bu projede kitabın yapımına en başından dahil olmuştur. Bruce Mau'un verdiği bu karar tasarımcıların proje üzerine, en az yazarın yaptığı araştırmalar kadar kendi birikim ve bakıș açılarını getirmesini sağlamıștır. "Koolhaas ve Mau, çağdaş mimarinin reddettiği tutarlı ahengi kitabın örgütsel ilkesi olarak görmüşlerdir" der Poynor (1998a, s. 235-236). Yani güncel mimarlığın kitap aracılığıyla bulunduğu beyanında, kitabın ortak yapım süreci de dahil olmuştur.

Kitabın editörü Jeniffer Sigler'in S, M, L, XL'nin giriş yazısında da belirttiği üzere ortak yazarlık, bir sayfanın ne renk olacağına karar vermekten daha katmanlı bir iştir. Kitabın baştan sona devam eden ve doğrusal anlatıyı reddeden kompleks doğası, Mau'yu kitabın yalnızca biçimsel görüntüsüne karar veren tasarımcı pozisyonundan yazar pozisyonuna geçirmeye yetmiştir (Novosedlik, 1994). Bu yüzden de S, M, L, SX örneği, herkesin bilmesi gerektiği gerçeği kapakta beyan etmektedir; bir tasarımcının kitabın içeriğe dair yapısına karar veriyor olması ve kitabın okunma biçimini doğrudan etkileyen görsel örüntüler kurması, Mau'nun adının kapakta yer almasına yetmektedir. (Karol ve Tanyeli, 2007).

Kitabın iç yapısı şöyle ilerlemektedir: S, M, L, XL, Foreplay başlığıyla açılan ilk sayfalarında Rem Koolhaas'ın dağınık ve "açık seçik" haldeki bürosundan bir görüntüyle okuyucuyla ilk diyaloğunu kurmaktadır (Görsel 18). Kitabın planlar, fotoğraflar, çizimler, günlükler, manifestolar ve makalelerle dolu karmaşı bir doğrusal okuması olsa da Mau, her bir sayfada yer alan metinleri belirli bir düzenden çıkarıp, metinleri sayfaların imkân tanıdığı ölçüde yerleştirerek okunma biçimini ileri-geri oynatılabilen sinema karelerinin yaratacağ kurmuştur (Poynor, 1998a, s. 235-236). Dolayısıyla S, M, L, XL'nin kendine has yapısı okuyucunun kendi okuma yolunu keşfetmesine olanak tanımaktadır.

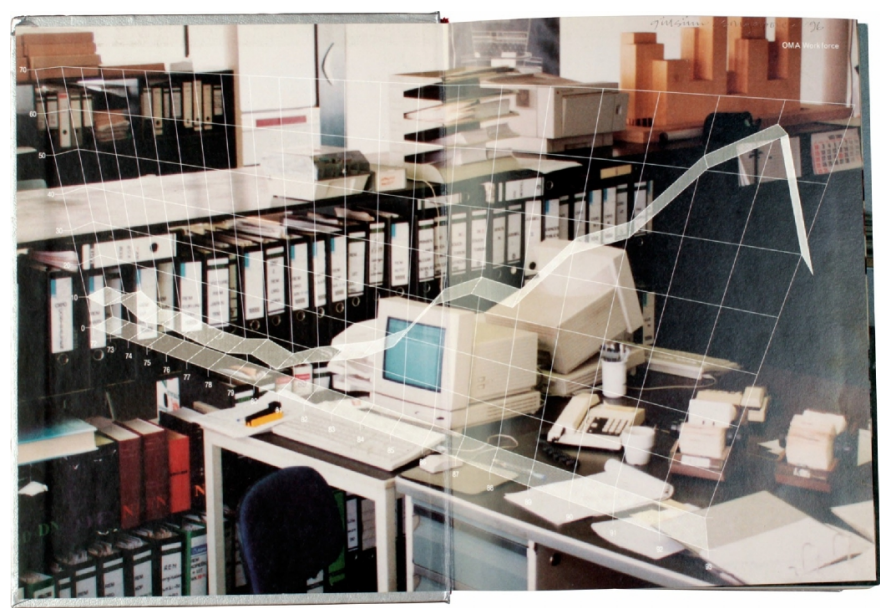

Görsel 18. S, M, L, XL Rem Koolhaas’ın çalışma masasının bulunduğu ilk sayfa 
Kitap, bir bilgi bloğu olarak düşünülmüştür. "Aile” adı verilmiş altı adet bölüme ayrılan S, M, L, XL'de her bir grup, içeriğine bağlı olarak farklı sayfa düzenleriyle temsil edilmektedir. Kitap boyunca birbirine paralel devam eden "sözlük" (Görsel 19) ve "aileler" birbirleriyle sürekli etkileşim halindedirler. Tipografi, tüm kitap boyunca zorunlu bir öğe olarak ilerlemek yerine sekanslar arasında ihtiyaç duyulduğu anda ortaya çıkmaktadır.

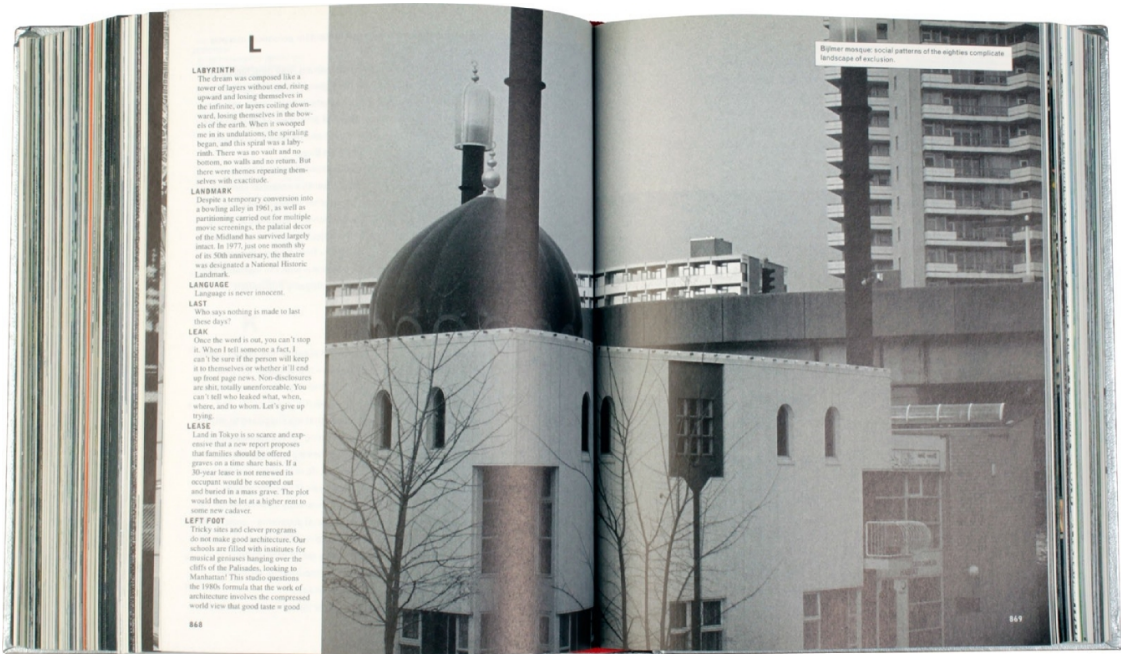

Görsel 19. S, M, L, XL sözlüğün görüldüğü bir sayfa

Hacim üzerine kurulan S, M, L, XL -mimarlığın tabiatına atfen- ölçeğe dayalı bir iç yapıya sahiptir. Kitabın kendisini adlandıran "Küçük, Orta, Büyük, Çok Büyük" tanımlı konsepti, şehrin ve mimarlığın karmaşık yapısındaki keskinlikleri daha da açık bir sınırla çizmek adına kitabın fiziksel yapısına yansıtılmıştır (Achten, 2014). Kitabın içerdiği projelerin ölçekleri doğrultusunda devam eden akış hem bölümlerin başlıkları hem de kitabın adıdır. Bu bağlamda içerik, biçimsel karşılığını bulmuştur. Kitap dört parçadan oluşmaktadır. İlk bölüm S, 166 sayfa $(8 \mathrm{~mm})$, M 282 sayfa $(14 \mathrm{~mm})$ L, 334 sayfa $(16 \mathrm{~mm})$ ve XL 475 sayfadır $(24 \mathrm{~mm})$ ve kitabın bölümleri, bölümlerde yer alan projelerin ölçekleriyle aynı oranda alan kaplamaktadır.
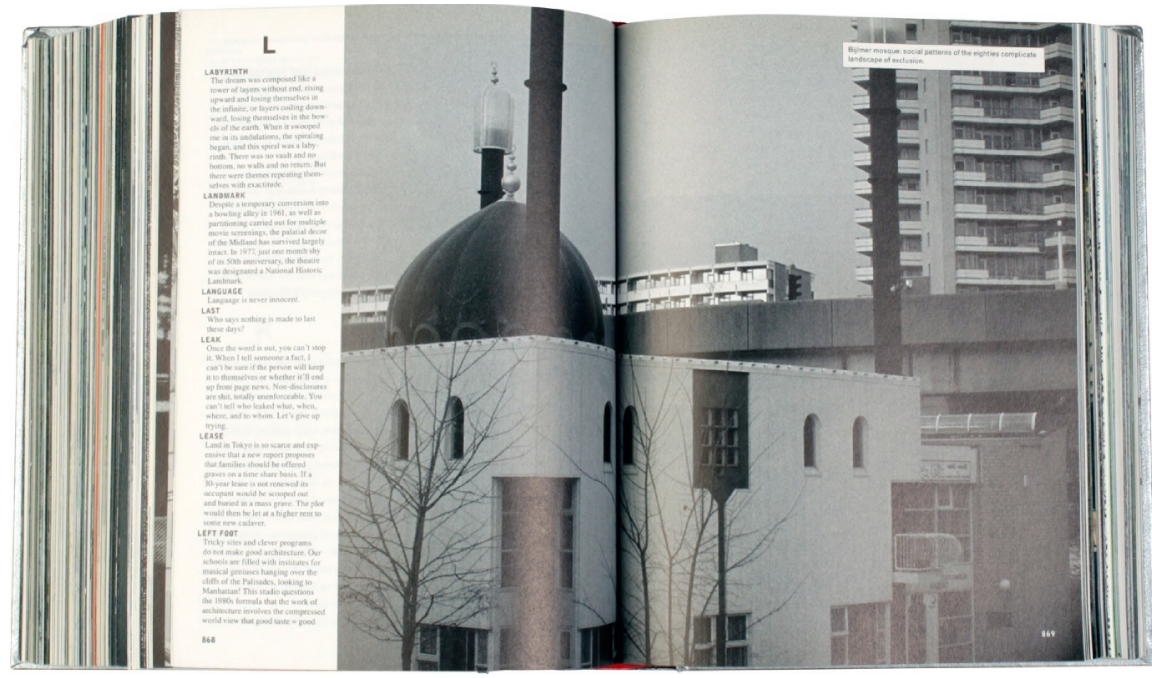

Görsel 20. S, M, L, XL'de bir kavram çerçevesinde metin ve görsellerin karşılıklı sayfalarda bir araya gelişine örnek

İçerisinde birçok küçük kitabı kapsayan bu melez kitabın kavramsal bağlayıcı kısmı ise kitap boyunca devam eden sözlüktür. Bu bölüm genelde sol sayfanın sol sütununda, bir projenin veya bir yazının tam ortasında rastgele belirip kaybolmaktadır. Bu sözlük ise kitabın editörü olan Jennifer Sigler tarafından, Koolhaas ve Mau'nun “endişelerini” dikkate alarak birçok kaynaktan yaptığı alıntı kolajlarıyla oluşturulmuştur (Poynor, 1998a). A'dan Z'ye ilerleyen sözlük, kitapla ilgili veya ilgisiz, birçok alanda tanınmış kişilerin alıntılarından bir araya gelmiştir. Karol, sözlüğü "kitabın parçalı yapısını ve ayrık sayfalarını bütünleyen; kitabı bir arada tutan dikiş ve yapıştırıcının sözel karşılığıdır" olarak nitelendirmektedir (2003, s. 104). 


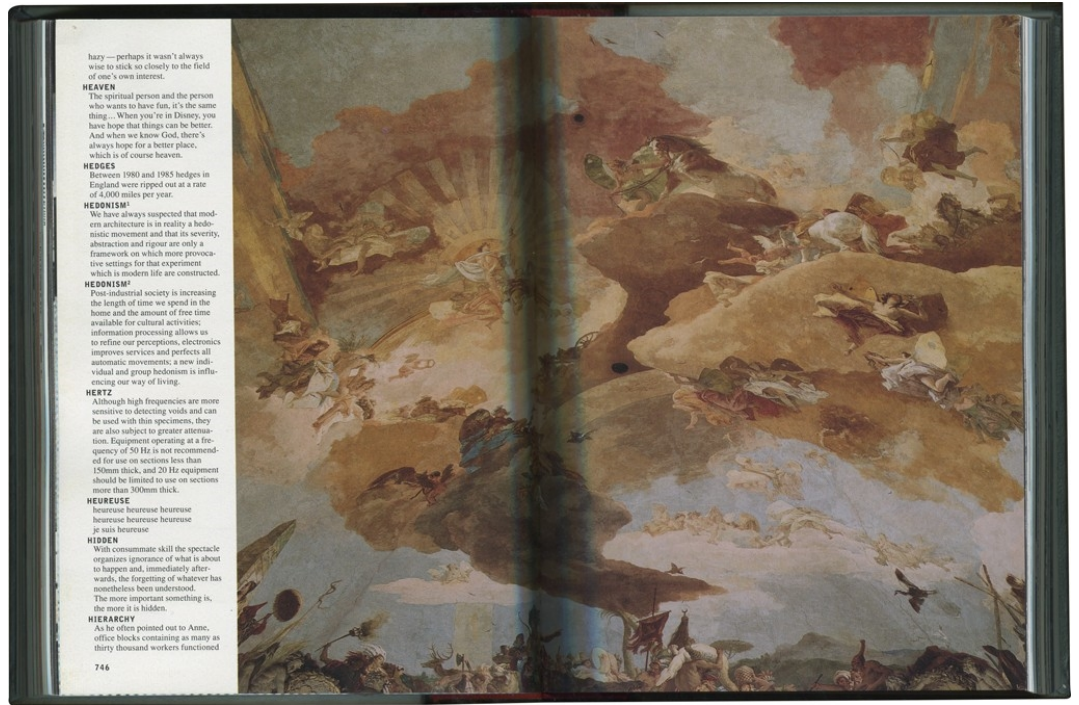

Görsel 21. S, M, L, XL sol sütunda akan sözlükte Heaven, Hiearchy gibi kavramlara karşıllı olarak kullanılan bir Rönesans tablosu

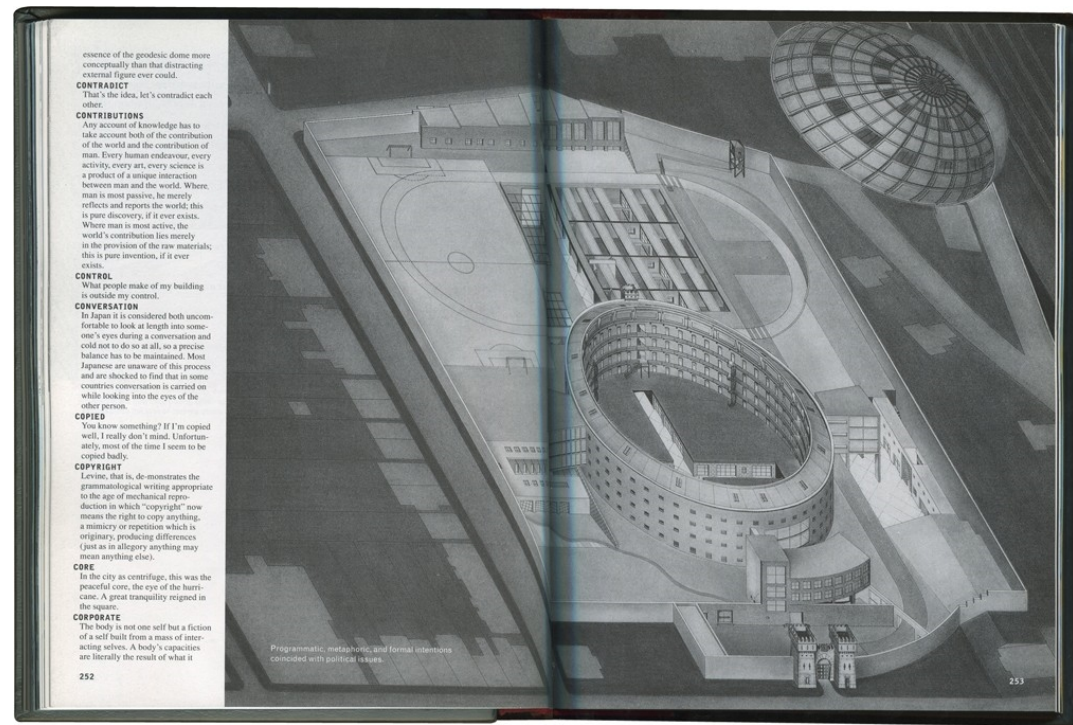

Görsel 22. S, M, L, XL sol sütunda akan sözlükte Control, Corporate gibi kavramlara karş1lık kullanılan bir hapishane planı görseli

Kitabın sonunda yer alan kronoloji, kitabın “içindekiler” görevini üstlenmektedir. Yazılar, tipografik kararlar, tekrar eden, etmeyen, büyük-küçük görseller, alıntılar, çizimler, rakamlar; hepsi kitabın tasarımla anlam üretme potansiyelini tetikleyen; bir arada veya bağıntısız birlikteliklerdir. Mau tarafından hesaplanarak karar verilen bu grafik dil, bütünde birleşen ancak ayrıntıda dağılmış görünen parçalardan oluşmaktadır. Tıpkı bir mimar gibi kitabı başından sonuna kadar inşa eden Mau, Karol'a göre bu grafik yorumuyla mimarların takıntılı olduğu ölümsüzlük nosyonuna da gönderme yapmıştır:

(...) yapı inşa eden bir mimar ölümsüzlüğünü garantilemiş midir? Yoksa bir yapıyı ya da mimarı ölümsüz k1lan üzerine üretilen metinler midir? (...) İçinde bulunulan bu elektronik bilgi çağında 'ölüm'üne kesin gözüyle bakılmış olan kitap hala ölümsüzlüğünü kendi tasarlamak isteyenlerin en gözde mecrası (Karol, 2003, s. 104).

İçeriğin grafik yorumla uyumuna, yazar ve tasarımcının birlikte çalışması sonucunda başından sonuna bir "kitap yapma" manifestosuna dönüşen S, M, L, XL, künyenin ardından gelen ve Postscriptum başlıklı son bölümünde yer alan bir "kütüphane" (Görsel 23) projesiyle manidar biçimde sona ermektedir. 


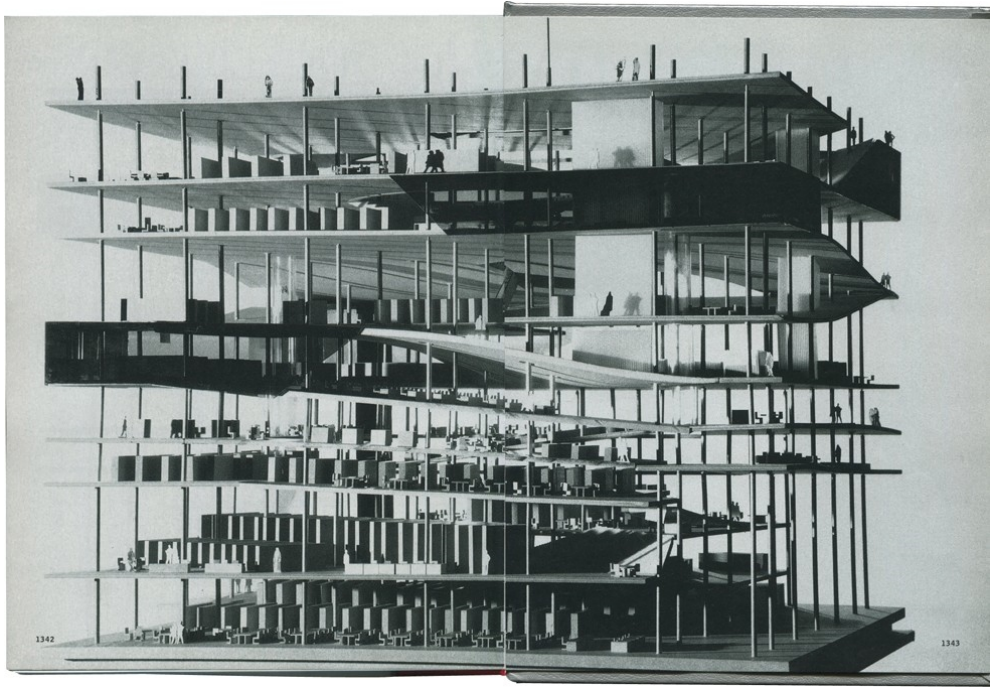

Görsel 23. S, M, L, XL kitabın kütüphane projesini içeren son sayfası

\section{SHV, Irma Boom: ThinkBook}

"Tasarımcı artık müşterilerin ihtiyaçlarını karşılayan hizmetçi olmaktan çok, tüm yaratım sürecinin bir parçası olan bir kişiye, bir yazara dönüşmüştür.” (Boom, 2008).

Son örnek olan ThinkBook (1996) (Görsel 24), önceki kitaplardan farklı olarak Irma Boom'un tek başına aldığı kararlar ve sorumluluklar doğrultusunda ortaya çıkmış bir projedir. 200 yıllık SHV petrol şirketinin prestij kitabı olan ThinkBook'un yapım süreci boyunca şirketin sahibi tasarımcıya sınırsız bir özgürlük tanımış, Boom ise bu özgürlüğü, tasarımıının bir kitabın içeriğini yazmak dahil, başından sonuna dek yapabilme fırsatı olarak değerlendirmiştir.

ThinkBook'un yapımı, Boom'un iki yıllık arşiv tarama ve üç yıllık tasarım süreciyle toplam beş yıl sürmüştür. 2.136 sayfası ve 3,6 kiloluk cüssesiyle Hollanda'nın bir tasarım simgesi haline gelen (Poynor 1998b, s. 237-240) Thinkbook, tasarımcıların yazarlığı yeniden ifade biçimi olarak düşündükleri 90'lı yıllarda yalnızca içeriğe biçim vermek değil, içeriğin bağlamını saptayıp yeniden oluşturması ve tasarımın tamamen tasarımcıya bırakılması konusunda atılmış cesur bir adımdır.

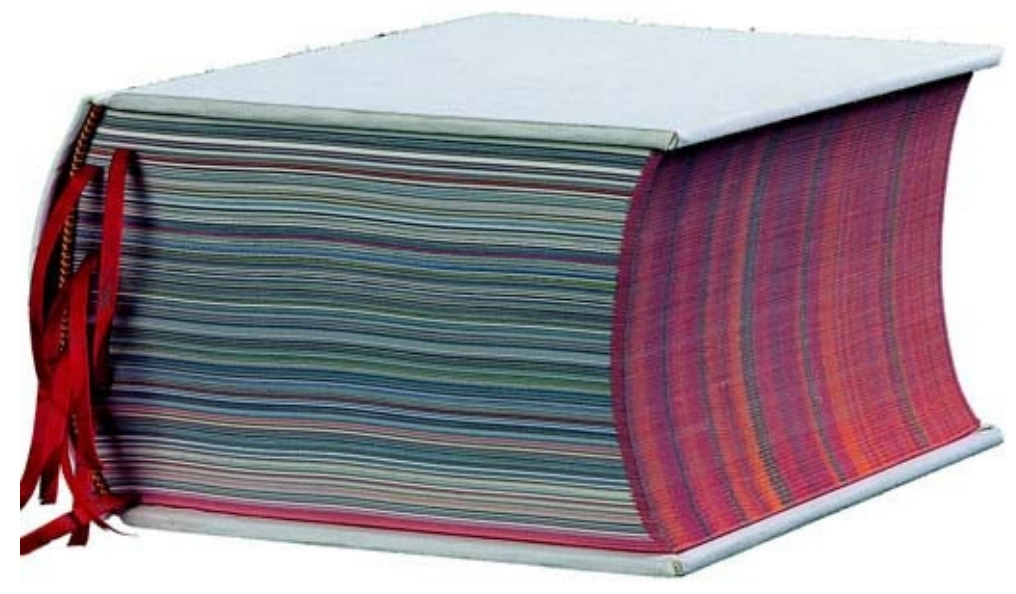

Görsel 24. SHV Think Book (1996)

Boom şirket ile ilgili hikayeleri yalnızca kelimelerle değil, bir araya getirdiği imajlar aracılığıyla anlatmayı tercih etmiştir. Betsky ve Adam'a (2004)' göre, kitabın içerik ve biçimine dair tüm kararları tamamen kendisinin veriyor olması, Irma Boom'u yalnızca kitabın tasarımcısı değil, aynı zamanda yazarı da yapmaktadır (s. 144).

Müşteriler için değil, onlarla birlikte kitap yapma fikrini savunan Boom, tasarladığı her kitabın bir anlamda ortak müellifi olmayı önermektedir. Bu yüzden tasarladı̆̆ı birçok kitabında yalnızca tasarımcı olarak değil, aynı zamanda içeriğe yön veren, kurgulayan ve içeriği yeniden oluşturan bir konumda durmayı tercih etmektedir. Boom 
(2010), kendi deyişiyle, verilen yönbilgilere, sınırlandırmalara ve bütçeye bakmaksızın, işveren ve işin içerisine dahil olan herkesle bir araya gelip proje fikrini birlikte geliştirmeyi tercih etmektedir.

Irma Boom, ThinkBook için 200 y1llık şirket arşivini kitap için bir araya getirmiş ve kitabı tümüyle bu arşiv malzemelerinden oluşturmuştur. Kitabın tasarlanma süreci, biçimsel görüntüsünü düşünmekten öte kitabın fikrini konuşmak üzerine ilerlemiştir. SHV firmasının sahibi Paul Fentener van Vlissingen, "alışılagelmedik bir kitap" isteğiyle kitabın diğer müellifi sanat tarihçi Johan Pijnappel ile birlikte Irma Boom'a sınırsız bütçe, sınırsız güven ve beş yıllık zaman vererek şirketin tüm dosyalarına erişme olanağı tanımıştır. Şirkete ait raporlar, konuşmalar, söyleşiler, mektuplar, şiirler, ilanlar ve aile üyelerinin fotoğrafları, kitabın yapısını oluşturan öğeler olmuştur. Tüm bu malzemeler "insan aklının çalışma prensibine dayanarak" gelecekten geçmişe doğru; 2096'dan şirketin kuruluşu olan 1799 yılına doğru ilerlemektedir (Poynor, 1998b, s. 237-240).
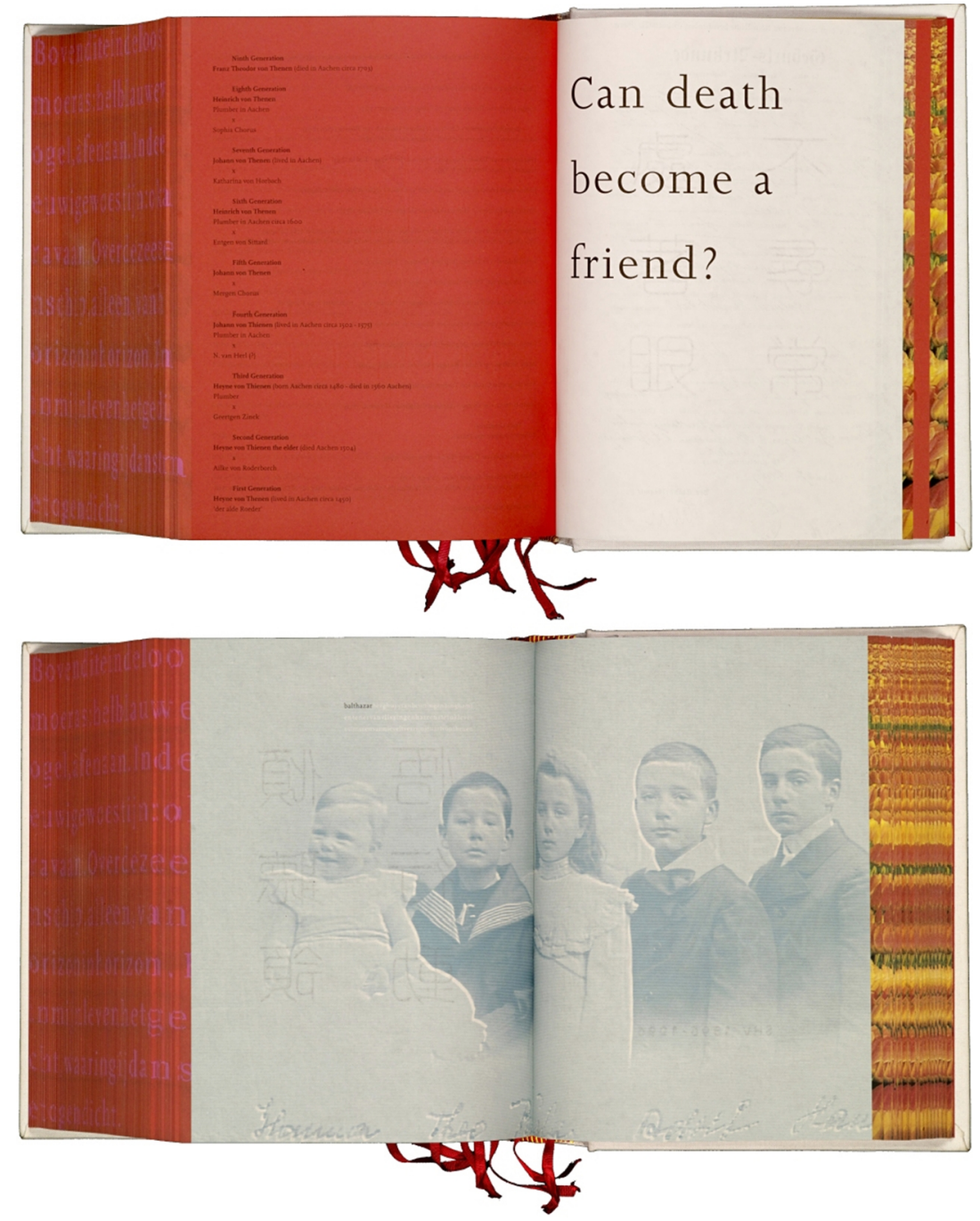

Görsel 25. SHV Think Book, şirketin arşivlerinden oluşturulmuş sayfalardan örnekler

Irma Boom kitabı komple bir nesne olarak ele almış ve boy, kâğıt, ağırlık gibi kitaba dair malzemeleri kitabı tanımlayan fikirlere dönüştürmüştür. Geleceğin belirsizliği fikrine dayalı olarak kitabın basıldığı yıla kadar olan tüm sayfalar mürekkep kullanılmadan, lazer kesim yöntemiyle içleri boşaltılarak oluşturulmuştur. Şimdiki zamana yaklaşan her sayfada boşluklar daha da daralmakta ve sonunda mürekkep basılı sayfalara geçilmektedir. Temelde "zaman” konseptiyle ilgili olan ThinkBook'u sayfaları, Irma Boom’un kendi ürettiği kâğıda basılmış, çok sağlam yapıştırıcı ile çok rahat açılıp çevrilebildiği bir ciltleme yöntemiyle kitap bir araya getirilmiştir. Dolayısıyla kitap fiziksel olarak da neredeyse 500 yıl çok iyi dayanabilecek ve asla zaman dışı olmayacaktır (Lommen, 2010). 

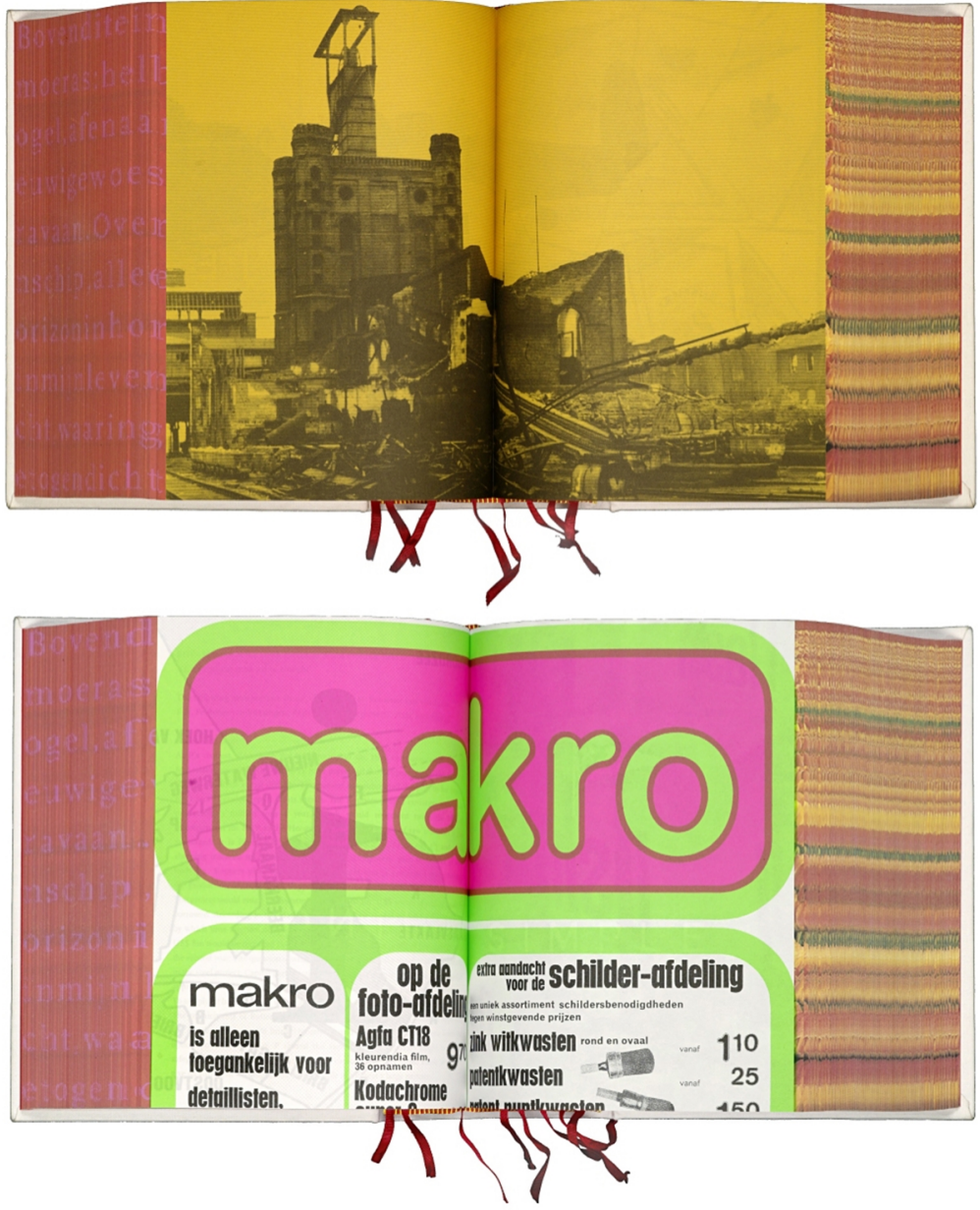

Görsel 26. SHV Think Book, şirketin arşivlerinden oluşturulmuş sayfalardan örnekler

Kitabın sağ kenarında Tulip tarlası imajı, sol kenarında ise kitap ilerledikçe beliren şiir görülmektedir. Kitap, kullanımına bağlı olarak okuyucu için gizli mesajlar taşımaktadır. Kitabın beyaz kapağı kirlendikçe yüzeyde geleceğe dair bir not belirmektedir. Kitabın sağ kenarı Hollanda Tulip tarlasının dokusuyla kaplanmış, sol tarafa açılan kenarında ise sayfalar ilerledikçe ortaya çıkan ve kitap bittiğinde tamamen okunabilen bir şiir yerleştirilmiştir (Boom, 2014). Akademik bir sıralama sistemi olmayan bu 2,136 sayfalık kitabın sayfa numaraları da yoktur. Kitabın zamansal akışı yalnızca belge, mektup, yayın gibi malzemelerin tarihlerinden okunabilmektedir. Bir yığın gibi görülen ThinkBook, Boom'a (2010) göre "düzenlenmiş bir yığın" olarak nitelendirilmektedir. Lommen ise böylesi cüsseli bir kitabı, artık bir kitap olarak değil, mimari bir yapı olarak değerlendirmektedir. Tasarımından basımına, fiziksel olarak üst düzey nitelikte olan kitap, kısa zaman içerisinde Hollanda'nın sembol tasarım nesnesi haline gelmiştir.

\section{Sonuc}

1970'ler ile başlayıp 1990'larda alevlenen, tasarımcının rolünün değişmeye başladığı ve daha bireysel kararlar ile aktif söylemlerde bulunduğu postmodern dönem içerisinde yer almış bu altı örnek, grafik tasarımcının yalnızca "içeriğe biçim veren" bir aracidan daha öte, söz söyleyen, içerik oluşturan ve içeriğin tüm anlam potansiyellerine yön veren bir "yazar" olabileceğini göstermektedir.

İçerik oluşturmak, yalnızca yazma eylemine bağlı değildir. İçerik, tasarımcının "şeyleri" ilişkilendirerek verdiği bir karar da olabilir. Bu makalede yer alan kitaplar, yalnızca tipografi ve görsellerden oluşan tasarım ürünleri değildir. Tasarımcının kendi bilgi birikimi, bakış açısıdır. Postmodern yazar tasarımcıların en güçlü belirtisi, tasarımcının metin üzerindeki kontrolü ele alışlarında kendisini göstermiştir. Grafik anlatıyı yazarlık diline çevirerek şahsen belirlenmiş çok cepheli bir form ile özgür yorumlama haklarını kazanmışlardır. Yazarlık fiili olarak üretilen bu kitaplar da tasarımından öte tasarımcısının düşünce biçimi olarak varlıkları meşrulaşmıştır. Bu meşruluk, tasarımcıya tıpkı bir editör ve küratör gibi "şeyleri belli koşullarda ve bağlamlarda bir araya getirme hakkı"nı verir. Bu haktan Modernizm döneminde bahsedilemezdi. Dönemin denklemi, "içerik-tasarımc1-tüketici" doğrusallığında ilerlerdi. Tasarımcılar anonim form vericilerdi ve meşhur "form işlevi izler" kriterine bağlı olarak tasarım yaparlardı. Ancak 1970'lerin dünyası ile birlikte bahsi geçen doğrusal denklem, birbiri içine girdi. Müşteri, 
içerik üreticisi, yazar, alıcı ve üretici gibi roller, bizzat tasarımcı tarafından belirlenmeye, kontrol edilmeye hatta rolleri çalmaya kadar ilerledi.

Grafik yazarlık, ortaya atıldığından bu yana sonlanmamış bir tartışma, sürekli bir sorgulama halidir. Yazar olarak tasarımcı tartışması bize sorun çözmekten öte, sorunun kendisini ortaya atan, soruyu dönüştüren ve yeniden yazan tasarımcıyı tanıtmış ve yalnızca müşteri ve sipariş odaklı tasarımcı konumunu daha özerk bir yere taşımıştır. Grafik tasarımcılar; sahip oldukları görsel malzemeleri bir araya getirme yeteneklerini, yalnızca görünür olanı tasarlayarak değil, yüzeyin altındaki içerikle birlikte entelektüel yapıyı kurarak da seslerini duyurabilmelidirler. Yazar tasarımcı olmak, özünde bir özerkliğe sahip olmak anlamına gelmektedir.

\section{Kaynakça}

Achten, H. (2014). Review: S,M,L,XL [Blog yaz1s1]. Erişim adresi: http://songgeism.blogspot.com/

Batur, E. (1994). Metin ile kitap arası yazar ile tasarımc1. Adam Sanat, 101, 20-22. İstanbul: Anadolu Yayınc1lık.

Berger, J. (Hazırlayan). (1972). Ways of seeing. [Televizyon Serisi]. Mike Dibb (Yapımcı). Erişim adresi: http://www.youtube.com/watch? $\mathrm{v}=\mathrm{LnfB}-\mathrm{pUm} 3 \mathrm{eI}$

Betsky, A., \& Adam, E. (2004). False flat: Why Dutch design is soo good? Londra: Phaidon.

Bilak, P. (2004). The book of probes. Erişim adresi: https://www.typotheque.com/articles/the_book_of_probes

Bilak, P. (2008). Ways of seeing book review. Erişim adresi: https://www.typotheque.com/articles/ways_of_ seeing_book_review

Bilak, P., \& Bailey, S. (2005a). The medium is the massage. Dot Dot Dot (X).

Bilak, P., \& Bailey, S. (2005b). The ways of seeing. Dot Dot Dot (9).

Boom, I. (2008). Irma Boom [Konferans kayd1]. ESAD Matosinhos Organisation, Küratör Andrew Howard. Erişim adresi: https://vimeo.com/37819812

Boom, I. (2010). Insights design lecture series: Irma Boom [Konferans kayd1]. Walker Art Center: Minneapolis. Erişim adresi: http://www.youtube.com/watch?v=nZbMEGxSN7s

Boom, I. (2014). Psychiatrist: The architecture of the book (Irma Boom) - part 1 [Konferans kayd1]. Psychiatrist: GSAPP The Graphis Project: New York. Erişim adresi: http://www.youtube.com/ watch?v=687FEZotW6I

Edgü, F., \& Erkmen, B. (1989). Book. İstanbul: Ofset Yapımevi Yayınları.

Erkmen, B. (1994). Memet Fuat'ın bir yazısı nedeniyle, kitap tasarımı ve Sevim Burak kitapları üzerine bazı notlar. Cumhuriyet Gazetesi, (3), 5.

Erkmen, B. (2007). Bülent Erkmen: Kitap yapmak? [Sergi metninden alıntı]. İstanbul: Marmara Üniversitesi.

Fuat, M. (1994). Yazar ile tasarımc1. Adam Sanat, 101, 5-19. İstanbul: Anadolu Yayınc1lık.

Gümüş, S. (1994). Yazınsal metin ve yorumun anlamı. Adam Sanat, 102, 37-41. İstanbul: Anadolu Yayıncılık.

Güngörmüş, N. (2003). A'dan z'ye Sevim Burak. İstanbul: Yapı Kredi Yayınları.

Heller, S., \& Mau, B. (2000). Reputations: Bruce Mau. Eye Magazine, 38(10), 12-20. UK: Quantum Publishing

Highmore, B. (2012). Then turn the page: Berger by the book. Journal of Visual Culture, 11(2), 124-126. Erişim adresi: http://vcu.sagepub.com/content/11/2/124.full.pdf +html

Hollis, R. (2010). Ways of seeing books. S. De Bondt ve F. Muggeridge, (Ed.), In Form of the book book. Belgium: Occasional Papers.

Hollis, R. (2013). Selected work: Ways of seeing. Erişim adresi: http://www.richardhollis.com/book-design/waysof-seeing

Karol, E. (2003). S, M, L, XL üzerine açık seçik notlar. Arredamento Mimarlık Dergisi, 100(63), 104-105.

Karol, E. (2012). Book. Jeff Wonders. [Podcast]. Bülent Erkmen ile söyleşi. İstanbul. Erişim adresi: http://jeffwonders.com/work/view/1205

Karol, E., \& Tanyeli, U. (2007). Esen Karol ile Uğur Tanyeli arasında bir e-posta söyleşisi. Kişisel görüşme ile ulaşılan kaynak.

Koolhaas, R., \& Mau, B. (1995). S, M, L, XL. J. Sigler (Ed.). New York: Monacelli Press.

Köksal, A. (1994). Zorunlu çoğulluk: Mimarlık ve sanatta dilin süreksizliği. İstanbul: ATT Yayınları. 
Köksal, A. (2010). Kitap tasarımı ve yanık Saraylar. Grafik sanatlar üzerine yazılar, 90. Erişim adresi: http://gmk.org.tr/publications/yazilar/mart-2010-sayi-90

Lommen, M. (2010). Irma Boom: Biography in books. Amsterdam: Grafische Cultuurstichting.

Lupton, E. (2009) Insights design lecture series: Ellen Lupton [Konferans Videosu]. Walker Art Center, Minneapolis. Erişim adresi: http://www.youtube.com/watch?v=6u0_K6t8wUE

Lupton, E.,\& Miller, A. (1999). McLuhan/Fiore, massaging the message. In Design, Writing, Research. New York: Phaidon.

Novosedlik, W. (1994). The producer as author. Eye Magazine, 15. Erişim adresi: http://www.eyemagazine.com/ feature/article/the-producer-as-author

Popova, M. (2012). How McLuhan, Agel and Fiore created a new visual vernacular for the information age. Erişim adresi: http://www.brainpickings.org/index.php/2012/02/10/the-electric-information-age/

Poynor, R. (1998). Authoring a labyrinth. Design without boundaries (s. 235-236) içinde. Londra: Booth- Clibborn Editions.

Poynor, R. (1998). XXXL. Design without boundaries (s. 237-240) içinde. Londra: Booth-Clibborn Editions

Poynor, R. (2000). Bruce Mau: The aura of power [Blog yazıs1]. Erişim adresi: https://designobserver.com/ feature/bruce-mau-the-aura-of-power/1917

Schnapp, J. T., \& Michaels, A. (2012). The electric information age book. New York: Princelon Architectural Press.

Thompson, M., \& Hollis, R. (2012). Ways of seeing design. Eye Magazine, 83. Erișim adresi: http://www.eyemagazine.com/review/article/ways-of-seeing-design

\section{Görsel Kaynakçası}

Görsel 1. The Medium is the Massage kitabının kapağı (2020). Erişim adresi: http://endinginabook.designwallah. com/wp-content/uploads/2011/10/e1.jpg

Görsel 2-4. Umut Altıntaş kişisel arşivi

Görsel 5. The Ways of Seeing (2020). Erişim adresi: http://assets.maharam.com/images/story_images/large/23/ stories_rock_b_968.jpg?1384922678

Görsel 6-23. Umut Altıntaş kişisel arşivi

Görsel 24. SHV Think Book (2020) Erişim adresi: https://www.amazon.com/1896-1996-Centennial-AlbumJubileumboek-Thinkbook/dp/B0089HP9TS

Görsel 25-26. SHV Think Book. (2020). Erişim adresi: https://www.kb.nl/themas/boekgeschiedenis/meerbijzondere-boeken/jubileumboek-shv 